\title{
UNE POPULATION QUI BOUGE: LES MIGRATIONS TEMPORAIRES ET SAISONNIÈRES À PARTIR DE VIANA DO CASTELO (XVIIle - XIXe SIÈCLES)
}

\author{
Margarida Durães ${ }^{\dagger}$, Emília Lagido $^{\star}$ y Cristina Caridade* \\ Universidade do Minho
}

\begin{abstract}
RESUMEN. El principal objetivo del estudio es el análisis de las migraciones internas que parten de Viana (Portugal) durante los siglos XVIII y XIX. En él no sólo se realizará un balance del fenómeno, sino que también se buscarán los procesos explicativos que ayuden a la interpretación del mismo, para lo cual se abordará desde una triple perspectiva: geográfica, económica y social. Se analizará, pues, la movilidad poblacional en general, poniéndola en relación con la estructura fundiaria, el paisaje agrícola y las formas de explotación de la tierra. Asimismo se estudiará el origen geográfico de los emigrantes mostrando qué parroquias en el departamento de Viana fueron las verdaderas proveedoras de los hombres que recorrieron los caminos de Portugal. Igualmente se tratará su perfil sociológico en relación con el trabajo que ejercían en sus lugares de origen y el empleo que desempeñaron luego en los lugares de destino. De este
\end{abstract}

Trabajo recibido el 3 de octubre de 2005 y aceptado para su publicación el 19 de enero de 2006.

+ Ce texte a été écrit depuis la conférence présentée au Séminaire "Histoire Sociale et Anthropologie Historique de L'Europe (XVIIIe - XXe siècles. Familles, transmission, migrations, rapports à la terre et aux marchés », sous la direction de Joseph Goy, Gérard Béaur, Rolande Bonnain-Dulon, Bernard Derouet et Jean-Paul Desaive, à l'Ecole des Hautes Etudes le 1 juin 2005. Je profite pour remercier les remarques de Joseph Goy, Bernard Derouet, Marie-Pierre Arrizabalaga, Pablo Luna et d'autres collègues qui ont été faites à l'occasion.

^ Investigadora do Núcleo de Estudos de População e Sociedade, do ICS, da Universidade do Minho, Mestre em História das Populações e Prof. do Ensino Secundário na Escola E. B. 2, 3 / S de Vila Nova de Cerveira.

* Aluna finalista do Curso de Geografia e Planeamento que connosco colaborou responsabilizando-se pela elaboração da cartografia apresentada neste trabalho. 
modo se espera comprender el papel que las migraciones jugaron en la organización social de la región del Miño.

Palabras clave: migraciones, pasaportes internos, estructura funciaria, complementariedad, origen social.

ABSTRACT. The primary objective of this study is the analisis of emigration from Viana do Castelo to other areas of Portugal in the 18th and 19th centurias. The phenomenom is quantified and subjected to geografphical, economic and social analysis in a search for explanatory processes. Population movements are related to land ownership structure, land uses and agricultural practices: the parishes supplying most emigrants are identified; and the emigrants occupations in their places of origin and new abodes are described. This study contributes to understanding of the role played by emigration in the social organization of the Minho region.

Keywords: migration, internal passport, land ownership structure, complementarity, social origins.

PARTOUT, l'image traditionnelle de la population de l'Ancien Régime totalement sédentaire n'interpelle pas les historiens depuis longtemps. Grâce aux études de démographie historique on connaît non seulement les glissements à courtes distances de tous ceux qui changent de paroisse pour se marier ainsi que le nombre des hommes qui sont morts loin de leurs lieux de naissance. Les études des institutions de charité donnent aussi des chiffres pour les malades et les pauvres aidés parce qu'ils sont loin de leur maison. L'historiographie d'émigrations à longue distance allant plus loin essaye d'esquisser une approche non seulement des chiffres des flux migratoires, mais aussi de trouver des explications qui puissent rendre compte des raisons qui poussent les hommes à partir.

Dans l'historiographie portugaise sont ces migrations de longue distance, considérées comme un facteur structurel de la société portugaise, qui ont attiré l'attention des chercheurs de toutes les sciences sociales ${ }^{1}$. L'émigration, abordée par les différents regards et perspectives des sociologues, des anthropologues, des géographes, des économistes et des historiens, s'est révélée un champ très fertile pour la production scientifique, qui a toujours envisagé le Portugal, et surtout le Minho, comme une région "répulsive" alors que le reste de la planète devenait une gigantesque région "attractive", puisque l'on trouve des minhotos partout. Pour expliquer le phénomène on a déjà écrit beaucoup sur les spécificités du contexte socio-économique du Minho. On a identifié les comportements démographiques de la population en relation avec

1 GODINHO, Vitorino Magalhães: Estrutura da Antiga Sociedade Portuguesa, Lisboa, Arcádia, 1975. 
les pratiques successorales et d'héritage. On a mis en relief le rôle de la structure foncière, ainsi que la petite taille de la plupart des exploitations agricoles, qui ne permettaient pas aux familles paysannes de vivre exclusivement de l'agriculture. On a également parlé du système agricole intensif alliant la production, dans les mêmes champs, de céréales et des produits nécessaires à l'alimentation de l'homme, au printemps et en été, et des herbes qui nourrissent les bêtes, en hiver. C'est à travers ce système agraire qu'on explique les hautes densités humaines qui peuvent se trouver dans la région. Mais, comme nous l'avons dit plus haut, tout ceci a servi à faire une interprétation des migrations à longue distance et pour de longues périodes, les migrations de "rupture", selon la désignation de Paul Rosental, qui n'ont concerné que quelques hommes ayant une capacité financière qui leur a permis de partir².

Dans l'ensemble de cette production scientifique, le nombre d'études produit par l'historiographie portugaise et celle des pays récepteurs de nos émigrés ne sont en aucun cas négligeable. Grâce à cela, nous connaissons d'une part l'ancienneté du phénomène et d'autre part les origines géographiques et sociales des émigrants, les facteurs qui ont influencé la décision du départ, les régions qui les ont accueillis ainsi que le succès ou l'insuccès de certains d'entre eux dans ces terres d'accueil ${ }^{3}$.

Pourtant, malgré tout ce qui a été dit et écrit sur le dépeuplement de certaines régions portugaises à cause de l'émigration, ces flux, à en croire António de Oliveira, ont été dépassés de plus de 30\% par les migrations internes au cours de la période 1891-19004. Selon cet historien, les migrations à l'intérieur du pays, ayant de profondes racines historiques, auraient atteint annuellement une énorme masse d'hommes (mais peu de femmes). Ceux-là, dans un mouvement d'aller-retour permanent, parcouraient le pays du Nord au Sud et d'Est en Ouest, soit, des régions de haute densité et pression démographique vers celles de basse densité .

2 ROSENTAL, Paul - André: "Maintien/rupture: un nouveau couple pour l'analyse des migrations", Annales E.S.C., no 6, 1990, pp. 1403 - 1431. Cf. du même auteur Les sentiers invisibles. Espaces, familles et migrations dans la France du $19^{e}$ siècle, París, Ed. E.H.E.S.S., 1999.

3 BRETTEL, Carolin: Homens que partem, Mulheres que esperam. Consequências da emigração numa freguesia minhota, Pub. D. Quixote, 1991; BRANDÃO, M. de Fátima: "O bom emigrante à casa torna?" en Actas do Colóquio Internacional sobre emigração e imigração em Portugal. Séculos XIX e XX. Lisboa, 1993; BENIS, Maria Ioannis: “A emigração de 1856 a 1875 vista de Viana do Castelo" en Revista de História Económica e Social, n 3, 1979; RODRIGUES, Henrique: Emigração e Alfabetização. O Alto Minho e a Miragem do Brasil, Viana do Castelo, Gov. Civil de Viana do Castelo, 1995; SERRÃO, Joel: $A$ Emigração Portuguesa, Lisboa, 1974.

4 OLIVEIRA, António de: "Migrações internas e de média distância em Portugal de 1500 a 1900", en EIRAS ROEL, A. (coord.): Migraciones internas y médium-distance en Espana en la Edad Moderna, Santiago de Compostela, 1993, p. 4.

5 SERRÃO, J. Vicente: “O quadro humano", en MATTOSO, José (dir.): História de Portugal, Lisboa, Círculo de Leitores, vol. 4, p. 54. L'auteur indique l'énorme décalage entre la densité au Minho et, par exemple, dans l'Alentejo: En 1801 le Minho aurait 26,3 feux par Km2 et l'Alentejo seulement 3,2. Dans le même sens sont les informations données par FEIJÓ, Rui: Liberalismo e Transformação Social, Lisboa, 
Ces migrations, au cours de plusieurs siècles, auraient conduit les habitants du Minho à Coimbra et aux Beiras, puis un peu plus vers le sud jusqu'à Lisbonne, Setúbal, Cartaxo et même plus au sud, vers les villes d'Alentejo (Évora, Olivença, Elvas, Campo Maior, Mourão ou Juromenha). Or, elles seraient également une conséquence des comportements démographiques, de la structure foncière, des dimensions des exploitations agricoles et du besoin de trouver des activités complémentaires apportant à la famille paysanne l'argent dont elle était privée à cause d'une production agricole insuffisante. C'est dans le même contexte économique et social des migrations extérieures que les déplacements intérieurs doivent être analysés et compris. Mais, à l'inverse de celles-là, ceux-ci atteignent la majorité des éléments masculins d'un grand nombre de familles du Nord-Ouest portugais.

Pourtant, les migrations internes ont toujours été oubliées et on en parle fort peu. En fait, leur rôle a été obscurci par l'excès de lumière porté par l'historiographie portugaise sur les migrations extérieures. Selon l'historien galicien, Eiras Roel, malgré leur importance, les migrations intérieures sont les parents pauvres de l'historiographie européenne ${ }^{6}$. De l'avis du même auteur, c'est le manque de sources, dont tous les historiens se plaignent, qui aurait provoqué cette situation, ainsi que la difficulté de soumettre certaines d'entre elles à un traitement statistique. Au Portugal, les rares études sur les migrations intérieures pour la période antérieure au XXe siècle, reposent surtout sur les registres de décès des personnes absentes ou sur les registres de mariages $^{7}$ et en quelques références à des entrées de malades dans les hôpitaux des $\mathrm{Mi}$ séricordias ${ }^{8}$. De ces travaux, il résulte un ensemble "asystématique, dispersé par des monographies à caractère local ou régional qui ne permet que d'ébaucher les lignes de tendance de la géographie des courants migratoires dans la période moderne"

A l'inverse de ce qui se passe dans l'historiographie française, qui se consacre à ce thème depuis plusieurs décennies, ainsi que dans l'historiographie espagnole, qui a

Ed. Fragmentos, 1992, p. 57. L'auteur indique une densité de 105,5 h/Km2 à l'arrondissement de Viana pendant que la densité moyenne de Portugal était 32,6h/Km2.

${ }^{6}$ EIRAS ROEL, António: "Migraciones Internas y Médium Distance en Espana en la Edad Moderna” en EIRAS ROEL. A. (coord.): Op. sup. cit., p. 61.

7 LAGIDO, Emília Pereira: Santa Maria de Âncora (1624 - 1910). População e Sociedade. Tese de Mestrado, Braga, Univ. do Minho, 2004, pp. 168 - 227; SOLÉ, Maria Glória Parra: Meadela, Comunidade Rural do Alto Minho: Sociedade e Demografia (1593 - 1850), Guimaraes, NEPS, 2001, pp. 313 - 338.

8 LOBO, Marta: Dar aos pobres e emprestar a Deus. As Misericórdias de Vila Viçosa e Ponte de Lima (sécs. XVI - XVIII), Ed. Sta Casa da Misericórdia de Vila Viçosa e Ponte de Lima, 2000, p. 653; ABREU, Laurinda: Memórias da Alma e do corpo: a Misericórdia de Setúbal na Modernidade, Viseu, Palimage ed., 1999; CARDADOR, José de Carvalho Asseisseira: Subsidios para o estudo da Santa Casa da Misericórdia de Salvaterra de Magos. Tese de Licenciatura, Fac. De Letras, da Univ. de Coimbra, 1970; COSTA, Américo da Silva: "O movimento do hospital da Santa casa da Misericórdia de Guimarães (1702 - 1728)", en Actas do Congresso Comemorativo do V Centenário da Fundação do Hospital Real do Espírito Santo de Évora, Évora, Hospital do Espírito Santo, 1996.

9 EIRAS ROEL, Antonio: "Migraciones Internas y Medyum-Distance ...", p. 62. 
investi ce secteur à partir des années 90,1 'historiographie portugaise a un grave déficit vis-à-vis des migrations intérieures. Notre connaissance de ce phénomène est partielle et épisodique, en ce qu'elle dépend de travaux entrepris par des anthropologues qui, dans la première moitié du XXe siècle, ont étudié les régions de Beiras, Ribatejo et Alentejo. Mais nous ne devons pas oublier non plus quelques-unes des plus belles pages de la littérature portugaise du milieu du XXe siècle qui, faisant des migrations intérieures un de ses thèmes favoris, nous fournit un tableau fictif pouvant servir de point de départ pour d'autres types d'analyses et d'autres accessions au phénomène.

Ainsi, cette étude vise à établir une approche non seulement du bilan du phénomène, mais aussi à trouver des procès explicatifs qui puissent aider à interpréter le phénomène des migrations internes aux XVIIIème et XIXème siècles. Afin de parvenir à nos objectifs, il faut essayer une approche différente de celles qui ont été menées jusqu'à présent.

Le phénomène migratoire sera abordé sous une triple perspective: géographique, économique et sociale.

En un premier temps, nous analyserons la mobilité de la population en général, en la mettant en relation avec la structure foncière, le paysage agricole, les formes d'exploitation de la terre et les produits cultivés, puisque les ressources économiques disponibles dans le lieu de départ sont en relation directe avec la population résidente dans une région déterminée ainsi qu'avec les facteurs à considérer dans la "répulsion" de ses excédents.

En un deuxième moment, nous détacherons de l'ensemble trois groupes professionnels afin d'établir une analyse comparative des comportements migratoires et ainsi de trouver les différentes raisons qui puissent expliquer son départ. Tout d'abord, les laboureurs, les journaliers et les valets de ferme. C'est parmi ces migrants plus directement liés à la possession de la terre et à l'exploitation agricole que nous pouvons rencontrer ceux qui sont les exclus de la succession et de l'héritage des exploitations agricoles et qui ont besoin de trouver des ressources au dehors de la maison paternelle. Ensuite, les professionnels liés au bâtiment et à l'artisanat. Maçons, peintres, charpentiers, cordonniers, tailleurs, font partie des groupes professionnels que nous pouvons trouver dans la société rurale du Nord-Ouest du Portugal. Leur existence s'explique par le caractère complémentaire de ces activités vis-à-vis du travail de la terre. Mais la croissance de leurs effectifs au-delà des besoins locaux les force périodiquement à s'en aller à la recherche de travail et d'un complément financier à leur activité agricole, ou d'un placement plus durable et plus rentable que celui qu'ils avaient dans leur terre d'origine. Enfin, nous ne pouvons laisser de côté le groupe des commerçants, d'employés de commerce, forains et colporteurs parce que 
ce sont eux qui font les liaisons entre le monde rural et le monde urbain en partant facilement et en aidant les autres à partir.

Dans cette étude nous chercherons, particulièrement, leur origine géographique pour connaître quels villages, dans le département de Viana, étaient de vraies pépinières de ces hommes qui parcouraient les chemins de Portugal. Nous ébaucherons également le profil sociologique de ces migrants en corrélation avec le travail qu'ils exercent sur leur lieu d'origine, mais aussi l'emploi qu'ils prendront à leur destination de façon à comprendre le rôle des migrations dans la réussite sociale. Pour finir, connaître les motifs qui ont mené à la décision du départ, tout comme les facteurs d'attrait des lieux d'accueil de ces groupes socioprofessionnels et la durée de leur absence, sont des facteurs qui pourront aider à expliquer le type d'organisation sociale dans cette région.

\section{Les sources}

Dans cette étude nous avons employé une source peu connue et très peu utilisée: les registres de passeports internes, qui ont existé au Portugal à partir du milieu du XVIIIle siècle ${ }^{10}$. Commerçants, négociants, colporteurs et forains, étudiants, religieux et ecclésiastiques, militaires, marins ou artisans des métiers les plus divers, laboureurs, "gagne-petits" et "hommes qui font les chemins" sont parmi les professionnels cités dans cette documentation, qui nous permet de dessiner le profil des migrants minhotos qui circulaient sur les routes de Portugal ou partaient en bateau vers la capitale ${ }^{11}$.

C'est sous le gouvernement du marquis de Pombal que ces passeports internes ont surgi, fruit du souci de contrôler les déambulations des hommes à l'intérieur du royaume. Ils ont été maintenus jusqu'au milieu du XIXe siècle. Comme les registres de passeports sont très sensibles à tout changement du point vu politique, militaire, économique et sociale, ils sont une des sources la plus intéressante pour suivre l'histoire du Portugal de ce période. Ainsi son analyse mérite quelques mots de notre part.

10 - En France, les passeports internes commencent á partir de 1790. Ils s'appliquent aux gens qui entrent á Paris et, comme au Portugal, ils sont destinés au contrôle des vagabonds et des errants. Le 3 ou 4 septembre 1791 ils sont abolis. C'est seulement à partir le 26 février 1793 qu'ils sont généralisés. La loi a été appliquée durant toute la première moitié du XIXe siècle dans toute la France. Cf. BECCHIA, Alain: " Voyages et déplacements au début du XIXe siècle (Études des passeports intérieurs conservés à Elbeuf) », Annales de Normandie, 41e année, nº 3, 1991, pp. 179 - 215.

11 Cf. BIDEAU, A., GARDEN, M. ; "Les registres de passeports à Trévoux pendant la Révolution: approche pour une anthropologie historique » en Études sur la presse au XVIII siècle. Les Mémoires de Trévoux. Centres d'Études du XVIIIe siècle de l'Université de Lyon II, 1975, nº 2, pp. 167 - 202. Après une analyse exhaustive du contenu des passeports, les auteurs présentent un véritable programme de recherche en anthropologie historique à partir du dépouillement de ces registres 
Créés par une ordonnance (Alvará de Declaração) le 25 juin 1760, ces documents ne concernaient au départ que les voyageurs se dirigeant vers Lisbonne ${ }^{12}$. Cependant, eut égard aux doutes et aux différentes interprétations permises par la loi, une nouvelle ordonnance est émise le 13 août 1760 qui, non seulement met au clair la portée de ce type de document, mais encore en étend l'application à l'ensemble du pays et à tous les portugais se déplaçant à l'extérieur de leurs districts d'origine ${ }^{13}$. Nous pouvons ainsi dire que ces passeports étaient “appelés internes parce qu'ils étaient un moyen de régler et de contrôler les déplacements des personnes (isolées ou en groupes) à l'intérieur du territoire portugais afin de renforcer la sécurité publique en évitant la déambulation de perturbateurs et de criminels"14. Cependant, le contrôle des sorties et des entrées et la sécurité de la capitale paraît être toujours le but principal de cette mesure, car le 31 mars suivant une nouvelle ordonnance déclare "qu'aucun vaisseau, carrosse ou monture à louer ou prêtée ne pourra sortir de la Ville de Lisbonne, et 3 lieues autour d'elle, sans un passeport du Ministre Intendant Général de la Police"15.

Au début du XIXe siècle, à cause des problèmes survenus à la suite des invasions françaises, il a été nécessaire de renforcer le contrôle sur les gens de passage ${ }^{16}$. Aussi, le 20 mai 1808, l'Intendant Général de la Police du Royaume fait afficher un avis où il est ordonné "qu'aucune personne de quelque qualité que ce soit puisse voyager ou sortir au dehors de son district sans le passeport signé par le corregedor ou les juges et rédigé par les greffiers (...); et si cette personne ne porte ou ne présente pas le passeport, elle sera mise en prison, à moins de se faire reconnaître par deux personnes parmi les plus connues du village, et alors on lui donnera un passeport signé aussi par ces deux personnes, qui seront ses garants obligés à n'importe quel comportement malhonnête (...).Et (...) j'ordonne que les Aubergistes et les autres personnes qui accueillent des passagers tous les soirs présentent une liste des personnes avec les noms, les lieux d'où elles viennent et ceux où elles se dirigent, et si elles portent un passeport (...)"17.

12 Alvará de Declaração de 25 de Junho de 1760 en Collecção das Leys, Decretos e Alvarás, que comprehende o feliz Reinado del Rey Fidelíssimo D. José o I, Nosso Senhor desde o anno de 1750 até o de 1769 e a pragmática do Senhor Rey D. João o V, do anno de 1749, Lisboa, Officina de António Rodrigues Galhardo, Tomo I, 1771.

13 Alvará de 13 de Agosto de 1760, en Collecção das Leys, Decretos e Alvarás ..., Op. sup. cit.

14 RODRIGUES, Henrique: Op. cit., p. 23; LOUREIRO, Joaquim Ferreira: Mobilidade Interna da População Portuguesa: os livros de registo de passaportes do concelho de Penafiel (1770 - 1833), Tese de Mestrado, Porto, F.L.U.P., 1997, p. 33.

15 Edital sur les passeports le 31 de mars 1761, en Collecção da Legislação Portugueza desde a Ultima Compilação das Ordenações Redegida pelo Desembargador António Delgado da Silva. Legislação de 1750 a 1762, Lisboa, Typografia Maigrense, p. 793.

16 Les invasions françaises ont commencé en 1808 et sont terminée en 1811.

17 A.M.V.C., Registo de Passaportes, Liv. nº 1204, fi. 1. 
Après la révolution libérale, la loi le 2 mai 1825 a établi "un ensemble étroit de procédures exigeant que les passeports soient émis en indiquant le lieu de destination et seulement pour le temps nécessaire au transit; que les propriétaires, marchands et forains puissent bénéficier de 3, 6 ou 12 mois, à leur demande, une information et accréditation fiable étant exigée; que tous soient obligés de solliciter un passeport pour sortir de leur lieu de résidence s'ils se dirigeaient à plus de 5 lieues de distance"18.

A première vue, le caractère obligatoire de ce type de document paraît limiter la liberté de mouvements de la population ${ }^{19}$. Cependant, ce n'est qu'en portant une telle autorisation que les ressortissants nationaux et les étrangers pouvaient circuler dans le pays sans courir le risque de se faire arrêter pour vagabondage ou mendicité non autorisée $^{20}$. Selon la législation, aucun déplacement ne devait échapper au contrôle, mais la multiplication des lois, des circulaires et des avis au cours de toute la première moitié du XIXe siècle semble indiquer le contraire. Cette nécessité de dicter des lois constamment sur le même thème montre bien que ce qui était stipulé et en vigueur depuis des décennies n'était pas respecté.

A partir de 1860, toutes les structures d'administration d'un état qui se réclamait de la liberté de circulation des marchandises, personnes et biens étant mises en place, il n'était plus possible de justifier de la surveillance des voyageurs. Les passeports internes furent donc abolis par la loi du 7 avril 1863. Depuis lors, les portugais ont la liberté de circuler dans tout le pays sans aucune restriction.

Bien que ces passeports aient été un document indispensable au long d'un siècle, ce qu'il nous en reste n'est qu'une petite partie des registres émis dans tous les départements et arrondissements du pays ${ }^{21}$.

A Viana, le corregedor du district a commencé à émettre des passeports le 26 septembre 1760. Ce qu'il nous en reste, pourtant, ne comprend que six livres de registres couvrant la période entre 1760 et 1836 . Avec des séries courtes, discontinues et hétérogènes, variant dans leur forme et leur contenu selon le greffier, les livres des registres de passeports de l'arrondissement de Viana sont le reflet de l'image politique, économique et sociale du Portugal à la fin du XVIIIe siècle et au début du XIXe.

18 MONTEIRO, Miguel: Migrantes, Emigrantes e “Brasileiros” 1834 - 1826. Territórios, Itinerários, Trajectórias, Fafe, Ed. Autor, 2000, p. 53.

19 OLIVEIRA, António de: "Migrações internas e de média distância ...., Op. cit., p. 3.

20 Le 18 août 1808, Pedro Rodrigues, célibataire, âgé de 25 ans, naturel de Valença, mais résidant à Viana, demande un passeport pour pouvoir mendier par tout le Royaume.

21 Selon le Recenseamento dos Arquivos Locais, du Département de Viana seulement les arrondissements de Arcos de Valdevez (1861-1863), Melgaço (1862), Ponte de Lima (1853 - 1880) et Vila Nova de Cerveira (1836 - 1842) ont conservé les livres des registres des passeports. Cf. Recenseamento dos Arquivos Locais. Câmaras Municipais e Misericórdias, Ministério da Cultura, Arquivos Nacionais/Torre do Tombo, Inventário do Património Móvel, vol. n³, Distrito de Viana do Castelo, Lisboa, 1996. 
Ce fonds commence avec le livre de registre des documents émis aux "personnes foraines et à toutes celles qui de cette ville se dirigent vers la ville de Lisbonne"22. Cinq autres livres suivent qui enregistrent tous les ressortissants du district et de l'arrondissement de Viana ayant sollicité un passeport pour aller dans n'importe quelle partie du royaume, tout comme les étrangers qui arrivent dans ce port de la côte atlantique nord du Portugal et veulent poursuivre leur voyage vers d'autres endroits, soit au Portugal soit à l'étranger.

Le décompte systématique des registres de passeports nous a fourni un volume de 14.159 sorties de Viana, par terre ou par mer, qui se distribuent annuellement comme il est indiqué dans le graphique $\mathrm{n}^{\circ} 1$.

En analysant le mouvement des enregistrements de passeports intérieurs, nous pouvons distinguer nettement deux périodes: la première, entre 1760 et 1767, correspond à la phase d'implantation de l'obligation de porter ce type de document si l'on voulait sortir de son district d'origine. Le registre atteint son apogée dans les années 1764/65. Il est interrompu en 1767, sans que nous ayons trouvé une explication plausible pour ce fait. Au cours de cette première période (1760/67), bien qu'avec quelques lacunes, nous pouvons affirmer qu'en règle générale, la qualité des registres est bonne.

Graphique $n^{0} 1$ - Evolution annuelle des demandes et des registres de passeports (1760-1837).

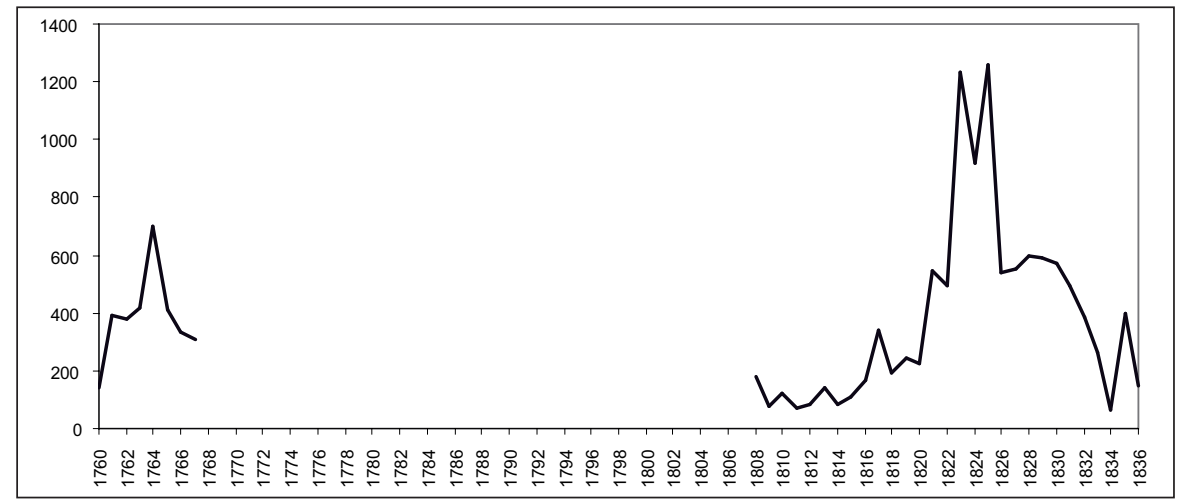

Source: A.M.V.C.: Livros de Registos de passaportes internos nº 1202, 1203, 1204, 1205, 1206, 1207.

Les greffiers ont même le souci de nous faire connaître les signes particuliers du visage du migrant: hauteur, forme et couleur du visage, forme du nez, couleur des yeux et des cheveux, s'ils portent ou pas une perruque, s'ils ont des marques de variole ou tout autre cicatrice ou défaut. Ils nous décrivent également les vêtements

22 - A.M.V.C., Registro de passaportes, Liv. nº 1202. 
avec un certain détail, comme s'il s'agissait d'un facteur d'identification. Ils oublient pourtant de nous indiquer la profession, l'âge ou l'état civil du demandeur.

Après une interruption de 41 ans, le registre des passeports est repris en un autre style. Recommencé en pleine période de guerre, quand une vague migratoire faible et irrégulière se fait sentir, il est le miroir des principales préoccupations des autorités civiles et militaires. Sans aucun doute, la période de guerre, de violence et de danger vécue dans les routes du nord, surtout pendant la deuxième invasion française, a comme effet immédiat la réduction de la circulation des personnes qui se déplaçaient traditionnellement à l'intérieur du pays. Mais cette même instabilité se réfléchit également dans le fonctionnement des organismes administratifs et, en conséquence, dans la qualité des registres. À cette époque, la préoccupation principale du greffier semble être la reconnaissance faite par le garant qui signe avec lui le registre, tout comme la présentation d'une licence militaire confirmant ou pas l'enrôlement dans l'armée et garantissant qu'il ne s'agit pas d'un déserteur. L'ensemble du registre se caractérise par le manque d'homogénéité des formulaires, ceux-ci dépendant du greffier de service qui changeait hebdomadairement.

Selon la loi, ces registres devaient consigner le nom du demandeur, son lieu de naissance, son domicile, son état-civil, son âge, ses signes physiques individuels (taille, cheveux, yeux, visage, barbe), son habillement, comment il se déplaçait (par terre ou par mer), la durée du voyage ou la durée de validité du passeport, l'itinéraire choisi et la destination finale. Quand le migrant ne voyageait pas seul, ceux qui l'accompagnaient devaient être décrits de la même façon.

Ces données d'identification devaient être complétées par des références aux aspects professionnels ou aux motifs du déplacement. Toutefois, ce n'est pas toujours le cas. L'âge, l'état civil, le lieu de naissance et le lieu de résidence sont souvent omis. La profession ou le métier du demandeur, ou le travail que celui-ci entreprendra dans son point de chute ne sont que rarement déclarés. C'est le moment où les registres de passeports sont de la plus mauvaise qualité. La majorité des greffiers se limitent à indiquer le nom du demandeur, son lieu de naissance et son lieu d'arrivée. L'enregistrement étant fait avec très peu de rigueur, parfois même quelques-unes de ces données sont omises.

Après cette phase de réduction de la mobilité, et aussitôt que la paix a été rétablie avec la révolution libérale de 1820, la fin de l'occupation anglaise et le retour de la famille royale de son exil au Brésil, qui ont permis le retour à la stabilité politique et un essai de récupération économique, les minhotos partent par volées vers le sud du pays, laissant quelques villages presque entièrement dépeuplés de leurs hommes d'âge actif .

Cette phase est toutefois de courte durée. Aussitôt après la mort du roi D. João VI, en 1826, le Portugal connaît une des périodes les plus troublées de sa vie politi- 
que, avec les luttes entre les libéraux et les absolutistes, qui ne s'achèveront qu'avec une guerre civile et le départ en exil de D. Miguel ${ }^{23}$. A partir de 1827, après un vrai boom de départs entre 1822/25, le registre de passeports adopte le format de presque tous les documents produits par les autorités libérales jusqu'à la fin de la période analysée: celui des "tableaux statistiques" 24 . Ces tableaux ne servent pas uniquement à enregistrer les passeports émis, mais encore à envoyer chaque mois au gouvernement central le nombre d'individus qui s'absentaient de la région ou d'étrangers qui se présentaient et faisaient enregistrer leur passeport pour pouvoir continuer leur voyage. Celui-ci est sans doute le moment de la plus haute qualité du registre de passeports internes puisque, désormais, nous avons systématiquement les informations qui manquaient depuis le début à notre étude. L'identification du demandeur est faite comme s'il s'agissait d'une Carte d'Identité. Mais le fonds du registre des passeports à Viana s'arrête en 1836 et il n'est plus possible de poursuivre l'analyse des migrations internes au travers de cette source. Nous sommes en pleine période de révolte contre les réformes que l'Etat libéral voulait entreprendre, et dans ces révoltes la population du Nord-Ouest a été un des principaux protagonistes. Les déplacements des minhotos auraient-ils été complètement interdits à cause de la méfiance des autorités vis-à-vis de leur comportement ? C'est une hypothèse à considérer dans l'avenir mais pour laquelle nous n'avons jusqu'à maintenant trouvé aucune preuve.

Malgré le caractère lacunaire des sources et toutes les insuffisances relevées antérieurement, nous avons tout de même essayé d'ébaucher une étude sociologique des migrants. Pour ce faire, nous avons créé une base de données où nous avons enregistré les informations qui nous semblent les plus pertinentes pour l'analyse que nous voulions entreprendre: le nom, l'état civil, l'âge, le lieu de naissance, le lieu de résidence, la destination, la profession, le type de déplacement, l'itinéraire, la durée du voyage, la durée de validité du passeport, les motifs du déplacement, les compagnons ainsi que leurs données d'identifications respectives et leur relation au demandeur. Le traitement statistique de ces informations nous a permis d'élaborer des tableaux, des graphiques et des cartes de synthèse qui nous fournirent une image quantitative des migrations internes et de leurs caractéristiques principales. A partir de cette analyse nous avons essayé de saisir les mécanismes des migrations intérieures et leur influence sur le modèle de la société minhota.

23 Convenção de Èvora-Monte assignée en mai 1834

24 Le Portugal, comme la plus grande partie des pays de l'Europe, est influencé par le développement de la statistique et de sa connaissance a travers les Manuels qui sont publiés à cette époque là comme par les Congrès qui sont réalisés pendant le XIXème siècle dans plusieurs capitales européennes. Pour une meilleure connaissance de ce sujet cf. BRIAN, Eric: « Statistique administrative et internationalisme statistique pendant la seconde moitié du XIXe siècle », Histoire \& Mesure, vol. IV (3 - 4), 1989, pp. 201 $-224$. 


\section{Dimensions et caractéristiques générales du phénomène}

Tout d'abord, nous devons faire ressortir, comme beaucoup d'auteurs avant nous, le caractère masculin des courants migratoires intérieurs, à l'égal de ceux qui concernaient de plus grandes distances et des durées plus considérables ${ }^{25}$. L'analyse quantitative des demandes de passeports et de leurs registres respectifs dans le département de Viana, montre que $96,8 \%$ des sorties étaient masculines, les femmes ayant une représentation insignifiante autour de 3,2\%. Ce sont les hommes qui se déplacent temporairement et saisonnièrement hors de leur région d'origine, alors que les femmes sont fondamentalement sédentaires ${ }^{26}$.

Graphique $\mathrm{n}^{0} 2$-Distribution des migrants par sexe (1760-1837)

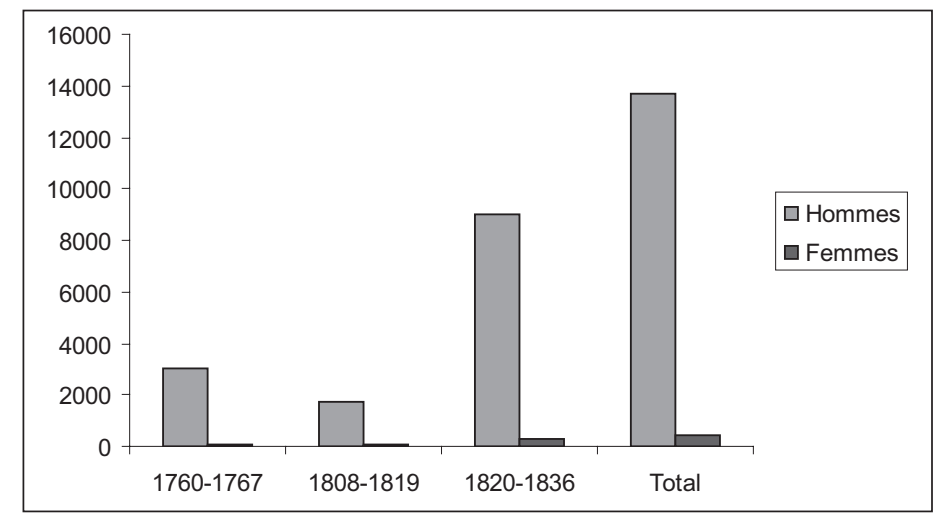

Source: A.M.V.C.: Livros de Registos de passaportes internos nº 1202, 1203, 1204, 1205, 1206, 1207

Toutefois, selon Rosental, cette image de l'immobilisme féminin doit être revue. En répartissant la population des communes en trois catégories (les sédentaires, ceux qui se déplacent à l'intérieur d'un petit rayon de 12/15 kms, et ceux qui partent plus loin) l'auteur affirme que les femmes, au moins dans le cas français, sont majoritaires dans les petits déplacements ${ }^{27}$. Cependant, dans le cas que nous étudions, ces déplacements ou glissements vers les villages voisins n'ont pas besoin de passeport et échappent totalement à notre étude. Selon cette théorie la faible présence

25 GREEN, Nancy: Repenser les migrations, París, P.U.F., 2002 ; MOCH, Leslie Page: "Bretons à Paris: Espace, travail, mariage. Devenir parisien", conférence présenté, le 15 mars 2005, au séminaire “L'Histoire comparée et les migrations contemporaines" dirigé par Nancy L. Green. Texte gentiment cédé par l'auteur.

26 Bien significatif de cette sédentarité féminine est le nom du livre de BRETTEL, Caroline: Homens que partem mulheres que ficam ..., Op. cit.

27 ROSENTAL, Paul-André: "La migration des femmes (et des hommes) en France au XIXe siècle », Annales de Démographie Historique, nº 1, 2004, pp. 107 - 135. 
de femmes dans le contexte des migrations intérieures vient confirmer ce qui a été dit précédemment: les déplacements féminins, quand ils se produisent, se réduisent à une aire proche de la commune d'origine ${ }^{28}$.

En tout cas, l'augmentation significative du nombre de femmes qui se déplacent au début du XIXe siècle (1808-1819) est digne de mention. Elle est due essentiellement à la conjoncture de guerre. Les femmes de Viana mariées à des militaires qui accomplissent leur service militaire dans des Compagnies placées à Porto, Coimbra ou Lisbonne demandent souvent des passeports pour ces villes, pour aller chercher ou rejoindre leurs maris, dont elles n'ont pas de nouvelles depuis longtemps ${ }^{29}$. Nous ne pouvons pas non plus éviter de noter que, dans la période suivante (1820-1836), les femmes augmentent timidement leur participation, s'intégrant en plus grand nombre aux flux qui se dirigent vers la capitale.

Le nom de ces femmes, son lieu de naissance et, parfois, leur état-civil mis à part, nous ne savons pas grand chose en ce qui concerne leur identification et les motifs qui les ont poussées à partir. Chercher un travail dans la capitale est certainement leur objectif. Mais de quel genre de travail s'agit-il ? La majorité de ces femmes se réfèrent à l'existence d'un membre de leur famille résidant dans leur lieu d'arrivée et qui fonctionnera certainement comme une base d'appui pour leur installation et la recherche d'un travail. Et sur les femmes qui demandent un passeport, nous ne savons plus rien, ce qui rendrait spéculatif tout autre apport à cette question ${ }^{30}$.

De toute façon, nous pouvons ajouter que cette participation restreinte des femmes minhotas à ces flux se doit, à notre opinion, à l'intensité des départs des hommes. Ceux-ci rendront difficile la sortie des femmes car leur main-d'oeuvre sera essentielle pour le labourage des terres et la continuité du système agraire minhoto. Mais l'intégration des femmes comme compagnons cache, d'une certaine façon, la composante migratoire féminine. Les femmes ne prennent que rarement l'initiative de

28 Sur le même sujet cf. ARRIZABALAGA, Marie-Pierre: « Migrations féminines - migrations masculines ... » Op. cit., p. 188 et p. 193.

29 Á partir 1808 il y a plusieurs femmes qui demandent un passeport pour aller visiter leurs maris qui servent dans l'armée. C'est le cas de Ana Teresa, âgée de 34 ans, native et résidant à Viana, qui demande un passeport le 24 juillet 1808 pour aller à Porto et à Coimbra voir son mari. Le 14 juillet 1810 Joana Vieira, de la commune de Mazarefes, demande elle aussi un passeport pour aller à Lisbonne voir son mari qui est à l'armée.

30 Selon Marie-Pierre Arrizabalaga, même dans le cas basque français il faut attendre la deuxième moitié du XIXe et le début du XXe siècles. A ce moment, le développement du marché du travail urbain qui s'enregistre va attirer les femmes aux villes et à la migration. Cf. ARRIZABALAGA, Marie-Pierre: «Comment le marché de l'emploi national et international a-t-il influencé les destins individuels au sein des familles basques et les modalités de transmission du patrimoine au XIXe siècle ? », en DESSUREAUlT, C., DICKI(NSON, J. A., GOY, J.: Famille et marché, XVIe - XXe siècles. Sillery (Québec), Septentrion, 2003, pp. 183 - 198. 
partir. Mais elles font partie du groupe qui accompagne certains demandeurs, surtout dans les cas où le départ semble être une décision définitive et familiale. Ainsi, les migrations féminines sont un autre sujet à prendre en compte, bien qu'il doive être traité au sein de l'organisation collective de ces déplacements ${ }^{31}$.

Comme nous l'avons dit plus haut, ces flux migratoires sont composés essentiellement par des hommes qui, individuellement ou en groupe, décident de tenter leur chance hors de leur terre natale. Quelques-uns, complètement sans terre, partent pour chercher un placement ou des salaires meilleurs que ceux qui étaient pratiqués dans cette région de haute densité démographique et de main-d'oeuvre abondante. D'autres s'absentent pendant quelques mois pour tenter d'obtenir des ressources financières pour compléter les revenus de leurs petites exploitations agricoles. Il y a ceux qui partent avec le savoir-faire acquis dans la pratique d'une activité artisanale, cherchant un travail et un plus haut salaire qui leur permettrait de faire quelques économies. Un nombre d'hommes significatif part, temporairement, pour mener à bien ses affaires. Et il y a encore ceux qui, à cause des spécificités de leur occupation, ont une vie itinérante et demandent constamment des passeports pour pouvoir circuler sans être considérés comme des vagabonds.

Ces déplacements sont surtout des migrations de "maintien"32. La majorité des hommes demandent un passeport pour l'aller et le retour, ou seulement pour 30 jours, trois mois ou peu de mois supplémentaires. On constate que la durée du passeport est presque toujours en liaison directe avec l'occupation du demandeur. En tout cas, c'est une indication qui nous permet d'affirmer que la plupart des migrants ont le retour toujours dans leur horizon. Ceci ne veut pas dire que l'absence ne puisse pas devenir plus longue et même définitive. Mais quand on veut retourner chez soi il y a toujours la possibilité de faire revalider le passeport dans le lieu où ils travaillent ou d'en demander un nouveau pour le retour, quand le précédent a perdu sa validité.

En plus d'être essentiellement masculines, les migrations internes, à l'inverse des extérieures, intègrent majoritairement des hommes mariés $(23,8 \%)$ dont la moyenne d'âge se situe dans les 32 ans. Les célibataires contribuent avec 19,7\% et les veufs, en très petit nombre, avec $1,7 \%$. Mais dans ce tableau général nous ne pouvons pas nous empêcher de faire remarquer que cette information est très insuffisante: le nombre de registres où l'état-civil n'est pas déclaré est supérieur à la moitié de l'échantillon $(54,7 \%)$.

31 Une proposition identique est suggérée par CHATELAIN, Abel: "Les migrations temporaires au XIXe siècle. Problèmes. Méthodes. Documentation », Annales de Démographie Historique, 1967, pp. $9-28$.

32 ROSENTAL, Paul - André: “Maintien/rupture: un nouveau couple pour l'analyse des migrations", Annales E.S.C., nº 6, 1990, pp. 1403 - 1431. 
D'autre part, les migrations temporaires sont également majoritairement rurales. Touts les arrondissements du département de Viana, aujourd'hui encore caractéristiquement ruraux, ont contribué à ces flux migratoires, bien que le chef-lieu soit celui qui a enregistré le plus grand nombre de sorties (Carte $n^{\circ} 1$ ). Nous devons vous alerter cependant sur la possible relativité de cette importance des sorties des natifs de Viana vis-à-vis les flux en provenance des autres arrondissements du Département. Les données que nous possédons concernent le registre des passeports sollicités dans la ville de Viana. Or, si nombre de ressortissants des arrondissements du Département venaient à Viana demander leur passeport, beaucoup d'autres, pour ne pas courir des risques inutiles ou parce qu'ils suivaient d'autres chemins, les demandaient dans leurs lieux d'origine. Il suffisait pour ce faire que dans le chef-lieu de l'arrondissement il y ait une autorité compétente pour l'émettre, soit, un juge. Toutefois, 69,8\% des migrants qui partaient de Viana étaient originaires du Département et, parmi ceux-ci, 83,1\% provenaient de l'arrondissement de Viana lui-même.

Si nous nous limitons maintenant au seul arrondissement, nous pouvons constater que ce flux présente une inégalité régionale aussi bien du point de vue quantitatif que qualitatif (Carte $\left.n^{\circ} 2\right)$.

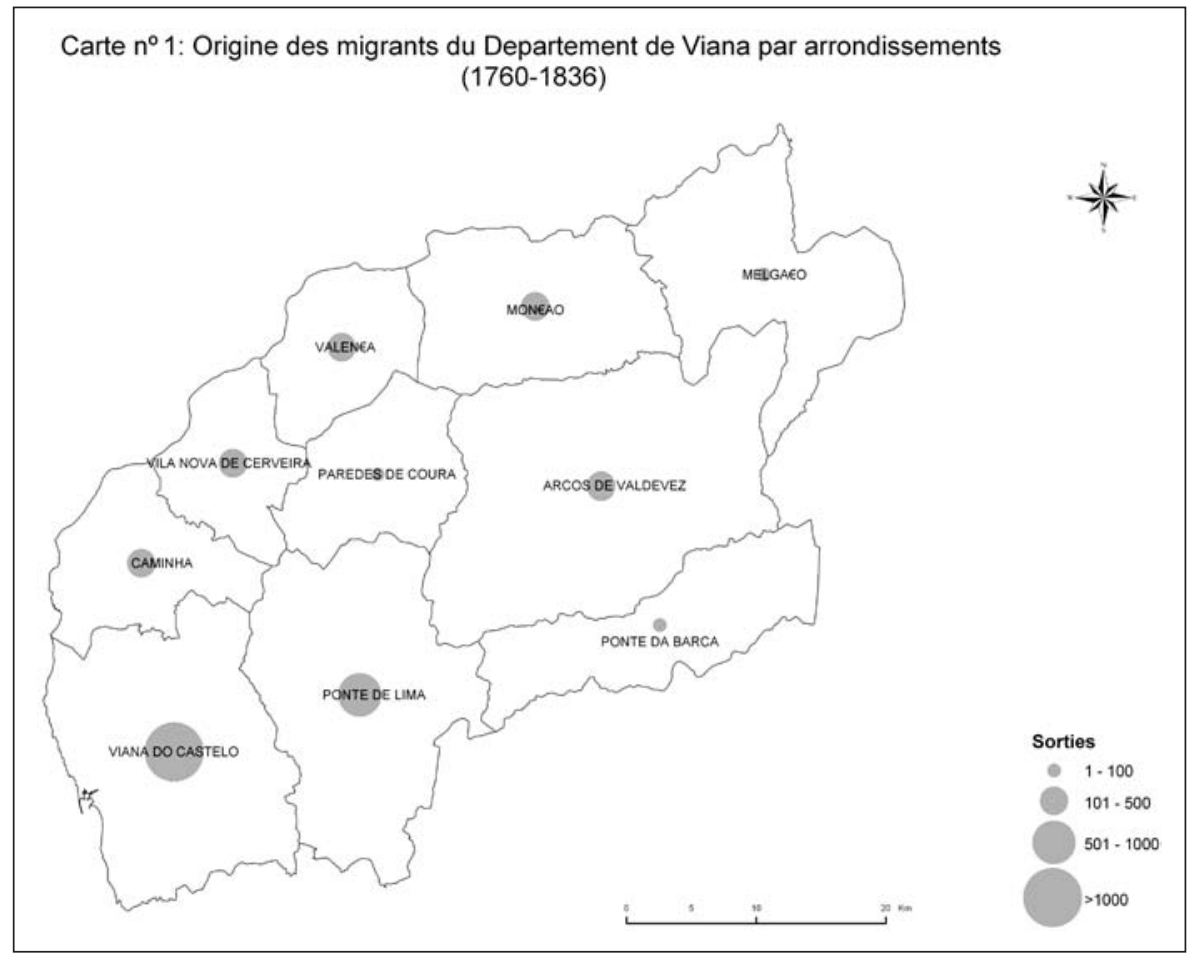


Carte $n^{\circ} 2$ : Origine des migrants de l'arrondissement de Viana par commune (1760-1836)

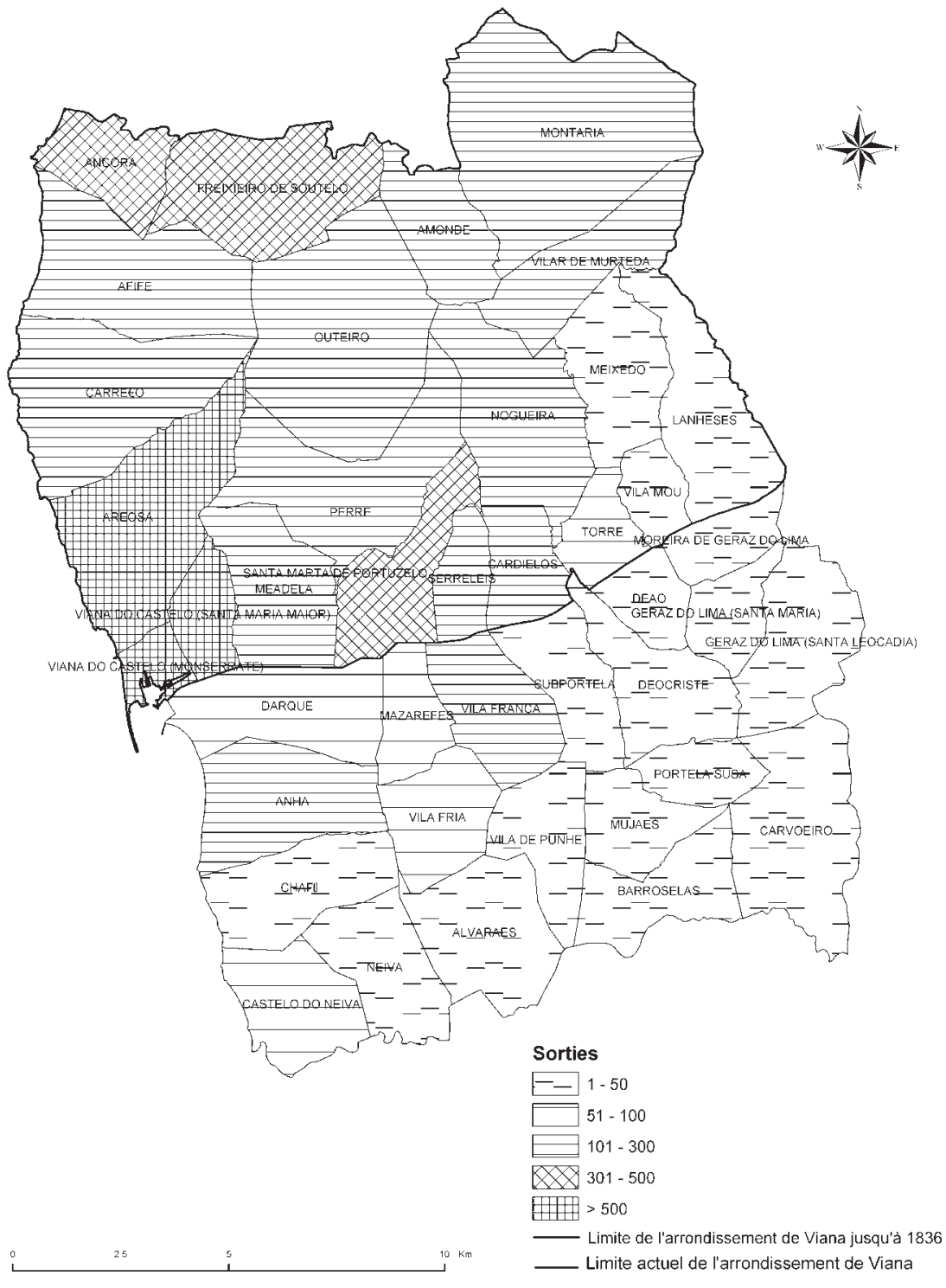


La ruralité de ces migrations demeure leur principale caractéristique. La ville fournit $37,4 \%$ des migrants de l'arrondissement et, dans ce nombre, nous devons insister sur la contribution des commerçants de tous genres tout comme la participation de marins et "hommes de la mer". Les communes rurales, à leur tour, contribuent avec $62,6 \%$ des natifs de l'arrondissement. Il faut noter cependant la forte contribution de certaines communes comme Areosa (934), Ancora (341), Santa Marta (425), Carreço (291) ou Soutelo (371), où l'on peut détecter une tradition migratoire profondément enracinée qui leur permettra de détenir la primauté dans la fourniture de migrants jusqu'au XXe siècle. Comme nous le verrons plus tard, cette même irrégularité se vérifie du point de vue qualitatif, car les deux paroisses qui grossissent le plus ces flux migratoires (Areosa et Santa Marta) sont celles qui ont envoyé le plus de travailleurs non qualifiés. Mais, comme l'affirme Bernard Derouet, "Ni tous les villages, ni toutes les familles, n'étaient pas engagés avec la même intensité dans l'activité migratoire" ${ }^{3}$. Pour cela, au niveau de l'arrondissement, nous constatons de profondes différences car des communes ne participent pas aux migrations alors que d'autres ont une forte tradition migratoire.

Mais de Viana partent aussi des voyageurs qui y font enregistrer les passeports amenés de leurs lieux d'origine ou en demandent de nouveaux. Ces individus sont, en majorité, originaires des zones rurales des arrondissements voisins appartenant au Département de Braga (Barcelos, Esposende) et ont choisi de partir par le port de Viana, contribuant ainsi au mouvement d'entrée et de sortie de la ville. Parallèlement à ces "voisins", un nombre significatif de natifs de Lisbonne ou d'autres villes du royaume (Porto, Braga, Guimarães, Matosinhos) passent aussi par Viana, y demandant ou revalidant leurs passeports. L'ensemble de ces individus contribue à la hauteur de $15,4 \%$ au flux migratoire.

Le nombre d'étrangers (12,2\%) qui transitent par Viana ou en sortent après y avoir vécu quelque temps n'est pas moins important. La situation privilégiée de son port de mer et l'importance que cette ville a atteint, au long du XVIIIe siècle, à cause du commerce avec le Brésil, l'ont rendue un lieu d'attraction de commerçants et de marins nationaux et étrangers ${ }^{34}$. Bien que de forme résiduelle, nous pouvons y trouver des ressortissants de l'Allemagne, de la Belgique, du Brésil, de la Hollande, de la France (141), de l'Italie (131), du Danemark, de l'Angleterre (118), des Etats Unis

33 DEROUET, Bernard: "Les paradoxes de l'ouverture: exclusion familiale et migrations dans la Creuse et le nord du Massif Central (XVIIIe - XIXe siécles) » en BOUCHARD, G., DICKINSON, J., GOY, J.,: Les exclus de la terre en France et au Québéc (XVIIe - Xxe siècles), Sillery (Québec), Septentrions, 1998, p. 312.

34 CAPELA, José Viriato: O Porto de Viana do Castelo no Contexto do Comércio Externo Português. (Análise à Balança Comercial de 1783, Viana do Castelo, 1987. 
d'Amérique, de la Suède, de la Suisse, de la Russie, de la Prusse, de la Pologne, de Malte, du Maroc, de Cuba, de la Terre Neuve et, tout naturellement, de l'Espagne. Parmi tous ces hommes, le nombre de migrants en provenance du pays voisin mérite d'être mis en évidence, et surtout celui des habitants de la Galice. Les Galiciens à eux seuls contribuent à la hauteur de 7,9\% (1116) au flux migratoire. Alors que certains d'entre eux passent par Viana pour rentrer chez eux, beaucoup d'autres, au contraire, cherchent du travail dans les contrées portugaises et s'y installent. Il y a aussi un groupe nombreux de Galiciens qui traverse le Portugal pour se rendre dans des localités du sud de l'Espagne, celui-ci étant accompagné de portugais qui, comme eux, se rendent dans les terres d'Andalousie et surtout dans la ville de $\mathrm{Cadix}^{35}$.

De même que dans d'autres régions rurales européennes, « la géographie de ces courants migratoires semble bien établie, les champs de déplacement bien définis, les directions et les rayons d'action extraordinairement variés. Il semblerait que chaque famille a une imagination suffisante pour trouver un secteur profitable en fonction des goûts et des qualifications de tout un chacun $»^{36}$.

Il faut dire qu'il n'est pas facile de connaître les qualifications professionnelles des individus intégrants les flux migratoires, puisque le pourcentage de ceux envers lesquels rien n'est dit dans les registres est très élevé (44\%). Les lacunes concernant la situation socioprofessionnelle des demandeurs de passeports peuvent être dues à leur simple omission par les greffiers, mais elles peuvent dériver également du manque de spécialisation de ces hommes. Notons, significativement, l'expression la plus utilisée dans le deuxième livre (1764-1767) pour désigner tous ceux qui partent à la recherche d'un travail sans avoir aucune qualification: "gagne-petit" (homem ganhão). Bien que révélatrice d'un sens typique régional, nous pensons qu'elle a le même sens que le générique "travailleur", le typique "cabanier" ou le plus commun "journalier", soit tous les sans terre qui devaient vendre leur force de travail pour survivre. Il est également difficile de classer des expressions telles que "fils-famille" (filho familia), "hommes qui font les chemins" (homens que andam caminhos), étudiant, mendiant ou “capitaliste", qui ne s'intègrent à aucune des catégories professionnelles proposées par le programme $\mathrm{HISCO}^{37}$. Si les quatre premières désignations peuvent rejoindre la catégorie des "sans occupation", nos doutes sont considérables quant à

35 Cf. aussi REY CASTELAO, Ofelia: "Les femmes “seules” du Nord-Ouest de l'Espagne: trajectoires féminins ....», Op. cit. De le même auteur voir aussi « Movimientos migratorios en Galicia, siglos XVI - XIX », en EIRAS ROEL, A. (coord.): Migraciones internas y médium-distance en España en la Edad Moderna, Santiago de Compostela, 1993, pp. 27 - 72.

36 BETEILLE, Roger: "Les migrations saisonnières en France sous le Premier Empire. Essai de synthèse », Revue d'histoire moderne et contemporaine, $\mathrm{n}^{\circ}$ 17, 1970, p. 428.

37 PELISSIER, Jean-Pierre, RÉBAUD, Danièle, NICOLAS, Dominique: La mobilité professionnelle en France aux XIXe et XXe siècles d'après les actes de mariage. HISMA Occasional Papers and Documents Séries $n^{\circ}$ 7/2004, Amsterdam, International Institute for Social History, 2004. 
la catégorie des "capitalistes". Nous connaissons cette désignation et nous savons qu'elle est appliquée aux individus qui ont une fortune personnelle et pratiquent le prêt à intérêt, ce qui correspondrait aux banquiers de nos jours.

Tableau $n^{0} 1$ - Distribution des migrants par leurs situations socioprofessionnelles (1760 - 1837)

\begin{tabular}{|l|r|c|}
\hline Catégories socioprofessionnelles & $\mathrm{N} / \mathrm{A}$ & \multicolumn{1}{c|}{$\%$} \\
\hline Professions scientifiques, techniques, libérales & 638 & $8,1 \%$ \\
\hline Directeurs et cadres administratifs & 50 & $0,4 \%$ \\
\hline Personnel administratif & 250 & $3,2 \%$ \\
\hline Personnel commercial et vendeurs & 1729 & $22 \%$ \\
\hline Travailleurs spécialisés dans les services & 168 & $2,2 \%$ \\
\hline Agriculteurs, laboureurs, journaliers, pécheurs & 1837 & $24 \%$ \\
\hline Ouvriers et manoeuvres non agricoles & 2162 & $28 \%$ \\
\hline Autres professions & 819 & $10,4 \%$ \\
\hline Sans professions & 211 & $2,7 \%$ \\
\hline Total de professions remplies & 7864 & $56 \%$ \\
\hline Cas omis & 6295 & $44 \%$ \\
\hline Total & 14159 & $100 \%$ \\
\hline
\end{tabular}

Malgré les difficultés et les lacunes, qui ne nous permettent pas de connaître que les qualifications professionnelles de $56 \%$ des demandeurs de passeports, nous croyons que cet échantillon est néanmoins suffisant pour nous permettre de compléter l'esquisse du profil sociologique des migrants de la région de Viana. Tout d'abord, permettez-nous d'attirer votre attention sur l'énorme diversité d'occupations de ceux qui circulaient dans le royaume: nous avons trouvé 358 désignations d'activités socioprofessionnelles.

Classées selon la typologie présentée par le programme HISCO, les occupations professionnelles les plus représentatives sont en relation directe avec la provenance géographique des demandeurs de passeports intérieurs. Les activités maritimes $(5 \%)$, le commerce $(22 \%)$ et les activités administratives et militaires $(4 \%)$ reflètent les aires urbaines alors que les travailleurs du bâtiment et grand nombre d'artisans $(27,5 \%)$, les laboureurs, les journaliers et les travailleurs en général $(23,9 \%)$ sont le reflet d'une origine rurale et des conditions de vie dans cette région de minifúndio. Mais nous pensons qu'il faut ajouter à ce dernier groupe une grande partie des migrants en provenance des communes rurales et pour lesquels nous n'avons pu relever aucune qualification professionnelle (44\%). Il y avait enfin un nombre significatif de migrants axés sur les métiers du bâtiment, mais aussi sur les activités artisanales. On peut aussi trouver des travailleurs moins spécialisés qui seront liés aux services domestiques ou aux travaux agricoles dans les grandes exploitations du sud du Portugal. A leurs côtés, sur les mêmes chemins, l'on trouve des forains, des colporteurs, de petits marchands ou des apprentis de commerce. 
Jusqu'à quel point cette diversité d'occupations a-t-elle eu des reflets sur le moment du départ et les destinations choisies? Le graphique $\mathrm{n}^{\mathrm{o}} 3$ nous montre que les migrations internes, considérées, depuis toujours, comme complémentaires de l'activité agricole, commencent au Printemps et se prolongent jusqu'à la fin de l'Eté. Deux moments différents sont préférés: la première vague de migrations débute en mars et atteint son plus grand volume en avril et mai. Au cours des mois suivants, il y a une légère diminution des sorties, bien que le nombre de départs soit toujours significatif. A partir du mois d'août et jusqu'à la fin d'octobre, nous avons une nouvelle vague, numériquement supérieure à la première.

Graphique $n^{0} 3$-Distribution des demandes et des registres

de passeports par les mois de l'année (1760-1837)

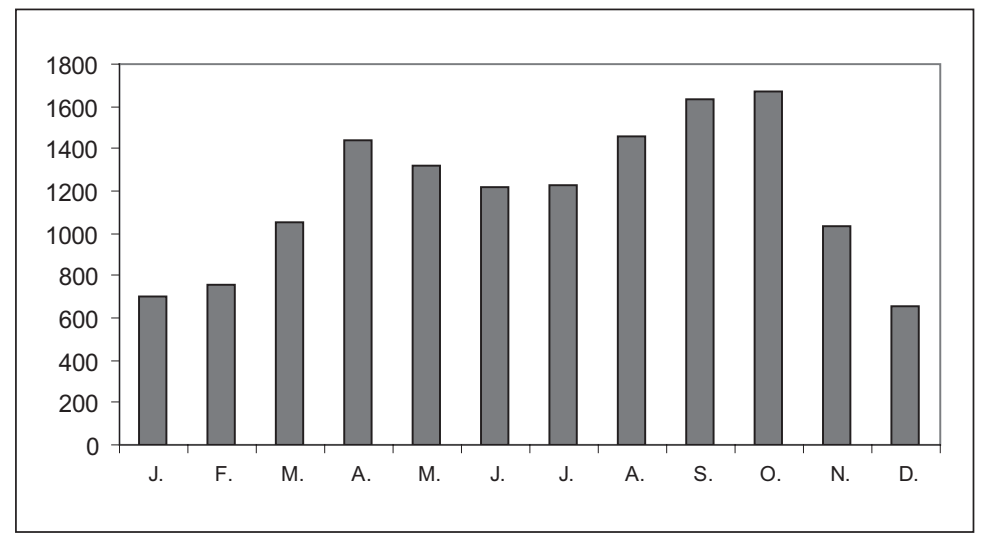

Source: A.M.V.C.: Livros de registos de passaportes internos $\mathrm{n}^{0}$ 1202, 1203, 1204, 1205, 1206, 1207

La constatation de ces deux comportements - une migration de printemps/été et une migration d'automne/hiver - confirme l'existence de logiques migratoires radicalement différentes dans la région du Nord-Ouest du Portugal. Cette diversité de comportements correspond-elle aux différentes occupations des migrants ? Qui sont les individus qui partent à chacun des moments de plus grand flux migratoire?

En répartissant les principales occupations sur les mois de l'année au cours desquels ces hommes préfèrent partir, nous arrivons aux résultats du graphique $n^{\circ} 4$, qui nous permettent une première approche du problème.

En premier lieu, nous pouvons constater qu'aucune occupation ne présente un comportement linéaire, car leurs représentants partent aussi bien au cours des mois de printemps que vers la fin de l'été ou même au début de l'automne. Ensuite, toutes les professions analysées, à l'exception des maçons, préfèrent les mois d'août et d'octobre pour leur départ. Finalement, les comportements divergents détectés, ne 
semblant pas être directement liés à la profession, nous indiquent l'existence de deux modèles différents.

D'une part, il y a une vraie migration de complémentarité. C'est un système qui ne permet le départ qu'après la fin des grands travaux agricoles, ou du moins celle de la moisson, et le début de la morte saison. Ce système a été adopté par ceux qui ont choisi de partir en août/octobre, et en premier lieu les laboureurs. Cependant, il y a toujours un nombre non négligeable de migrants de ce groupe qui partent au printemps, qu'ils possèdent ou pas des exploitations agricoles.

Graphique $n^{0} 4$ : Distribution des migrants par leurs professions et le moment de départ (1760-1836)

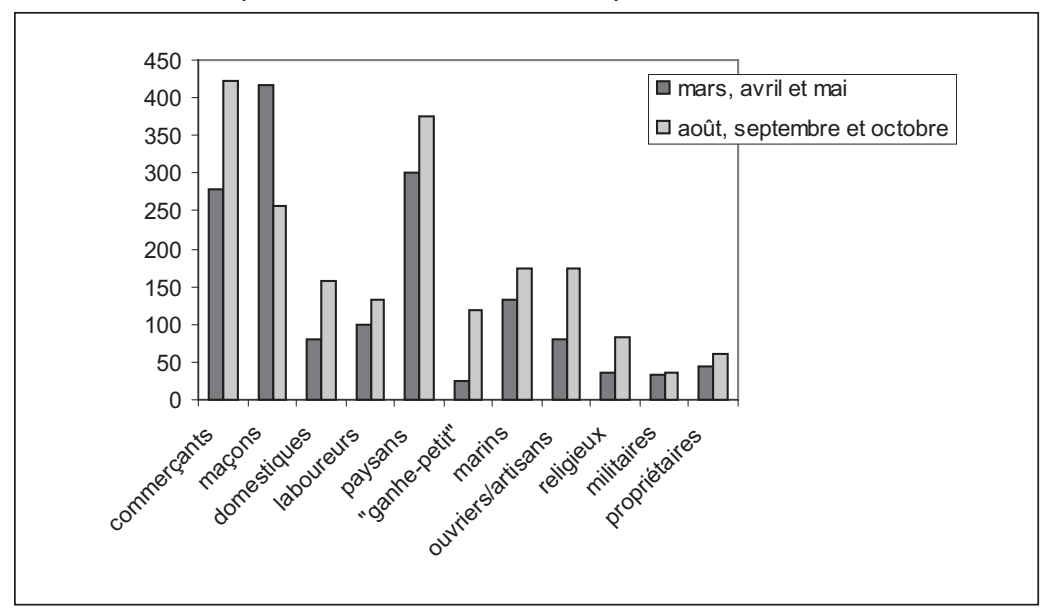

Source: A.M.V.C.: Livros de registos de passaportes internos n 1202, 1203, 1204, 1205, 1206, 1207

A l'inverse de ce qui a été affirmé pendant longtemps, les activités complémentaires développées par les hommes n'ont pas toujours lieu au cours de l'hiver, une morte saison du point de vue agricole. Les hommes qui partent à partir du mois d'avril (moment des semailles) et ne reviennent qu'au début de l'automne, quand les moissons sont terminées, semblent plus soucieux de la complémentarité financière que leur travail peut apporter au budget familial qu'à la complémentarité de leurs occupations. Le départ d'un grand nombre d'hommes dans la période du plus intense travail dans les champs minhotos ne semble pas avoir mis en cause la viabilité des exploitations. Soit parce que les hautes densités humaines de la région continuaient à fournir la main-d'oeuvre nécessaire aux travaux agricoles, soit parce que les femmes qui restaient étaient suffisantes pour assurer ceux-ci ; il faut signaler que le système agricole minhoto n'a pas subi de crise au long des XVIIIe et XIXe siècles par manque de main d'oeuvre. De cette façon, les hommes, qu'ils soient de petits propriétaires 
ruraux ou des artisans qui, à côté de leur maison et de leur jardin potager, possèdent un atelier, ou encore des "cabaniers" ou journaliers qui cherchent du travail dans une région où il y a de la main-d'oeuvre excédentaire, partent vers des régions du pays où il leur est offert de meilleures occasions de travail.

Nous reviendrons sur ce sujet nécessairement, quand nous ferons l'étude comparative des comportements migratoires de certaines de ces catégories. Peut-être l'analyse plus fine et exhaustive des différents facteurs qui conditionnent ces migrations permettra-t-elle l'intelligibilité du phénomène. Cependant, il semble que le "rythme des migrations soit déterminé par des choix individuels qui s'inscrivent de fait dans une stratégie familiale" 38 , indépendamment de l'occupation principale des éléments masculins du groupe domestique.

En ce qui concerne les destinations préférées des minhotos, nous pouvons dès à présent avancer que nous faisons face à un flux migratoire qui se dirige surtout vers les deux plus grandes villes du royaume, et seulement ensuite vers d'autres centres urbains de moyenne et de petite dimension. Au cours de la période concernée, le lieu qui attire le plus les minhotos, car il leur offre des possibilités de travail en plusieurs secteurs économiques, c'est Lisbonne. Entre 1760 et 1836, la capitale a attiré 6.464 migrants, ce qui correspond à 45,7\% de l'échantillon.

Centre politique, administratif, militaire et économique, la capitale fait appel à tous les genres de personnes. Elle attire une grande diversité de commerçants qui s'y dirigent pour mener à bien leurs affaires. D'autre part, après le tremblement de terre de 1755, la capitale a été transformée en un immense chantier de reconstruction qui a absorbé beaucoup de main-d'oeuvre spécialisée du bâtiment, ainsi que des travailleurs indifférenciés. Lisbonne, lieu des décisions politiques et militaires, attire aussi non seulement les chefs militaires des différents régiments qui viennent y recevoir des consignes mais également tous ceux qui vont servir les Compagnies dont le siège est dans la capitale. Mais la capitale, principal centre de consommation, est aussi le lieu idéal pour que les gens de métiers viennent développer leurs activités et pour les apprentis commerçants qui veulent se lancer dans le commerce. C'est ici également que les jeunes trouvent facilement un placement comme domestique, puisque c'est ici qu'habitent les élites qui ont besoin d'eux pour les travaux domestiques et la conservation de leur prestige et de leur statut. Nobles, fonctionnaires, militaires, domestiques, esclaves, commerçants, apprentis de commerce, maçons, artisans, paysans, travailleurs non qualifiés, marins sont parmi les professionnels qui se dirigent vers la capitale pour les motifs les plus variés.

38 MOULIN, Marie-Annie: «Les maçons de la Haute-Marche au XVIIIe siècle », Annales de Démographie Historique, 1986, p. 230. 


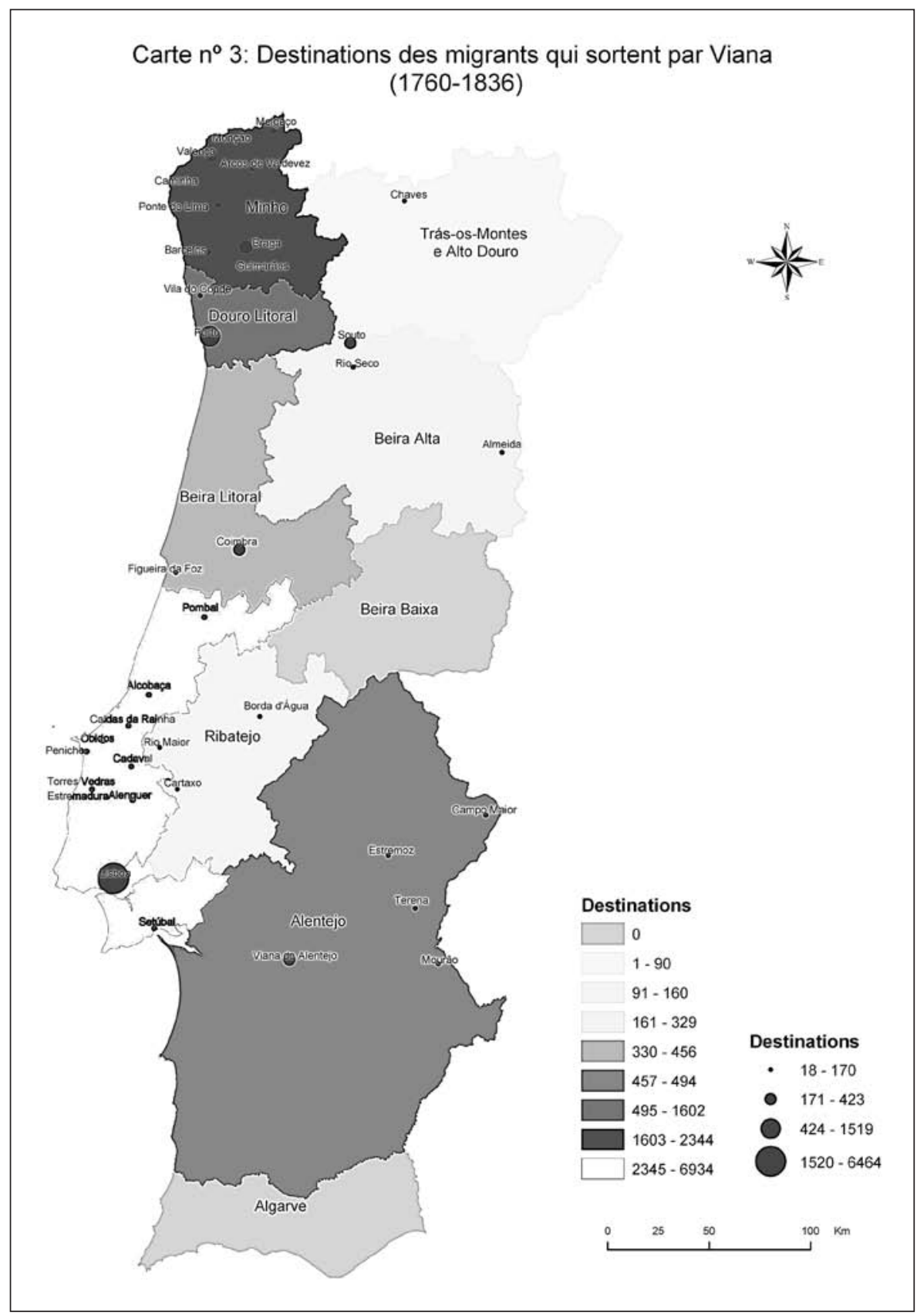


En plus de la capitale, les minhotos sont attirés par la deuxième ville du royaume. 1.519 migrants sont partis vers Porto, ce qui correspond à 10,7\% de notre échantillon. Etant un des plus importants centres commerciaux et industriels du Nord du Portugal, cette ville ne pouvait manquer d'attirer un grand nombre de commerçants qui y menaient leurs affaires, mais aussi de marins et de gens de métiers. Braga (3\%), comme centre religieux, et Coimbra (2,5\%) comme principal pôle culturel du royaume et grand noyau économique du Centre, viennent ensuite. De petites ville du Minho même (Valença, Monção, Melgaço, Caminha, Ponte de Lima, Barcelos, Guimarães) ou d'autres régions du pays (Chaves, Figueira da Foz, Óbidos, Pombal, Penafiel) sont le reflet de la grande diversité des destinations que nous pouvons trouver dans ce type de mobilité.

Mais les grands, moyens ou petits centres urbains n'ont pas été les seuls endroits à attirer les habitants du Minho. Bien qu'essentiellement urbaines, les migrations des minhotos se sont également dirigées vers l'Alentejo, le Ribatejo, la Beira Alta et 1'Estrémadure, provinces vers lesquelles sont partis surtout des maçons, des "gagne-petit" et des travailleurs indifférenciés. Il y a encore un nombre significatif de négociants, marchands forains et colporteurs qui demandent des passeports pour circuler, pendant toute l'année, à l'intérieur même de la province du Minho. Enfin, nous ne pouvons passer sous silence le petit nombre de voyageurs qui demande un passeport à Viana pour se diriger vers Bordeaux $(0,1 \%)$ ou l'Espagne $(0,1 \%)$ et surtout la Galice $(1,9 \%)$..

$\mathrm{Au}$ XIXe siècle, les destinations se diversifient à tel point que notre échantillon présente 376 localités différentes vers lesquelles sont partis ceux qui ont demandé leur passeport à Viana. Les destinations les plus significatives apparaissent sur la carte $n^{\circ} 3$.

Comme nous avons déjà pu le constater, les comportements migratoires sont très diversifiés, aussi diversifiés que les genres de vie, les structures socioprofessionnelles, les structures mentales ou encore les traditions régionales ${ }^{39}$. C'est pourquoi une analyse plus détaillée des comportements migratoires des principaux groupes qui constituent notre échantillon s'impose. Selon Nancy Green, seule l'étude comparative des migrations peut nous conduire à dégager les contraintes structurales de l'expérience individuelle, à remarquer la différenciation dans les parcours des groupes, et à distinguer si possible l'essence du phénomène ${ }^{40}$. Et comme nous l'avons déjà

39 POUSSOU, Jean-Pierre: "Les mouvements migratoires en France et à partir de la France de la fin du XVe siècle au début du XIXe siècle: approches pour une synthèse ", Annales de Démographie Historique, 1970, pp. 11-78.

40 GREEN, Nancy: 'L'Histoire comparative et le champ des études migratoires », Annales E.S.C., $n^{\circ} 6,1990$, pp. 1335-1345. 
dit plus haut, pour entreprendre cette approche comparative nous avons choisi trois groupes professionnels différents.

\section{Une approche comparative des migrations}

\subsection{Paysans, laboureurs, journaliers et valets de ferme}

Viana do Castelo, comme tout le Minho, est une région qui se caractérise par le grand parcellement et la dispersion des exploitations agricoles. Celles-ci sont formées, en général, de petites parcelles de qualité très diverse permettant la polyculture intensive grâce à la force de la main-d'œuvre abondante et au système d'irrigation implanté depuis les temps les plus révolus. Le système de champ - pâturage, comme il est désigné par Orlando Ribeiro, a permis le développement d'un système agraire en parcelles bordées d'arbres ou de vignes et sujettes à une exploitation intensive grâce à l'utilisation d'engrais et de l'eau des fleuves, rivières, ruisseaux, fontaines et sources qui sont dispersés à travers tout le paysage du Minho ${ }^{41}$.

Cette agriculture intensive a été développée en exploitations de petite taille tournées vers la culture du maïs et une petite polyculture. Pendant l'été, la production était destinée à la consommation des hommes. Pendant l'hiver, les champs servaient à la production de pâturages qui alimentaient les animaux. Les vaches, les bœufs, quelques moutons et brebis, avec le vin et les céréales en surplus, au cours des années de bonnes récoltes, étaient les seuls produits vendus sur les marchés régionaux. C'est cette agriculture de subsistance qui a conduit le petit paysan au besoin d'avoir d'autres activités qui puissent compléter les petits profits issus de l'agriculture. Ces comportements n'ont pas seulement engendré une incertitude socioprofessionnelle mais ont permis aussi une meilleure insertion des femmes dans les activités agricoles.

Sans vouloir tomber dans les exagérations de Oliveira Martins ${ }^{42}$ qui enregistrait, déjà au XIXème siècle, l'importance du rôle de la femme paysanne du Minho, nous devons constater, comme lui, que les femmes sont la principale force de travail de l'agriculture du Minho. Et pourquoi ?

Des 55,6\% de migrants dont nous connaissons l'activité, 29,1\% sont laboureurs, journaliers, valets de ferme et ouvriers en général qui partent de leurs communes rurales vers un autre coin du royaume à la recherche de travail et d'un profit qu'ils ne trouvent pas sur leur terre natale. La majorité des petites exploitations agricoles étant entretenues par la main-d'œuvre familiale, « le problème de cette région provenait du

\footnotetext{
${ }^{41}$ RIBEIRO, Orlando: “Agricultura”, in D. H. P., Porto, 1971, pp. 60- 67.

42 MARTINS, J. P. de Oliveira: Portugal Contemporâneo, $3^{\circ}$ vol., Lisboa, 1953, pp. 52-53.
} 
manque d'opportunités locales d'emploi» ${ }^{43}$. C'est pourquoi les hommes partent alors que les femmes soutiennent, avec leur travail, les exploitations familiales.

La caractéristique typiquement masculine des migrations internes se maintient dans ce groupe socioprofessionnel même si l'on peut trouver ici un nombre réduit de femmes qui prennent l'initiative de partir, surtout depuis 1820 .

Tableau $\mathrm{n}^{\circ} 2$. Répartition des migrants du secteur primaire par sexe et par période (1760-1836)

\begin{tabular}{|c|c|c|c|c|c|c|c|c|}
\hline Sexe & $1^{\circ}$ période & $\%$ & $2^{\circ}$ période & $\%$ & $3^{\circ}$ période & $\%$ & Total & $\%$ \\
\hline Hommes & 284 & 99,3 & 78 & 97,5 & 1884 & 98,1 & 2246 & 98,3 \\
\hline Femmes & 2 & 0,7 & 2 & 2,5 & 36 & 1,9 & 40 & 1,7 \\
\hline Total & 286 & 100 & 80 & 100 & 1920 & 100 & 2286 & 100 \\
\hline
\end{tabular}

Source: AMVC: Livros de registo de passaportes n 1202, 1203, 1204, 1205, 1206, 1207

L'analyse du profil sociologique des paysans, laboureurs et journaliers qui migrent met en évidence la présence d'un nombre important de hommes jeunes. Comme nous indique le tableau $\mathrm{n}^{\circ} 3$, il y a une forte incidence $(60,3 \%)$ d' hommes qui se déplacent dans une tranche d'âge de 16 à 35 ans. A partir de 36 ans, la tendance diminue atteignant des valeurs dérisoires pour les plus de 56 ans. Ils partent jeunes, - la moyenne d'âge de ce groupe avoisine les 31 ans - célibataires ou aussitôt après le mariage. Les premiers, les célibataires, partent dans le but de se procurer l'argent nécessaire à leur mariage et à leur installation ; les seconds, s'en vont gagner de l'argent pour rembourser les dettes contractées envers l'Eglise, l'Etat, le seigneur et même envers certains membres de la famille.

Tableau $n^{\circ}$ 3: Répartition des laboureurs, travailleurs et journaliers par période et par groupe d'âge (1760-1836)

\begin{tabular}{|l|c|c|c|}
\hline Âges & $\mathbf{1 7 6 0 - 6 7}$ & $\mathbf{1 8 0 8 - 1 9}$ & $\mathbf{1 8 2 0 - 3 6}$ \\
\hline $0-15$ & 11 & 4 & 39 \\
\hline $16-25$ & 104 & 16 & 368 \\
\hline $26-35$ & 87 & 13 & 352 \\
\hline $36-45$ & 49 & 4 & 254 \\
\hline $46-55$ & 14 & 6 & 143 \\
\hline $56-65$ & 3 & 2 & 69 \\
\hline $66-75$ & 3 & 0 & 18 \\
\hline Inconnus & 15 & 35 & 677 \\
\hline Total & $\mathbf{2 8 6}$ & $\mathbf{8 0}$ & $\mathbf{1 9 2 0}$ \\
\hline
\end{tabular}

Source: AMVC: Livros de registo de passaportes $\mathrm{n}^{0} 1202,1203,1204,1205,1206,1207$

43 FEIJÓ, Rui Graça: Liberalismo e Transformação Social, Lisboa, Ed. Fragmentos, 1992, p. 99. 
Bien que majoritairement mariés $(53,2 \%)$, nous avons dans ce groupe un nombre significatif d'hommes célibataires $(44,1 \%)$ et très peu de veufs $(2,7 \%)$ (Graphique $\left.n^{\circ} 5\right)$.

À cet important nombre de célibataires qui se situe bien au-dessus de la moyenne générale trouvée dans la caractérisation dominante de ces migrations, les travailleurs, les journaliers et les valets de ferme contribuent beaucoup. Sans famille, sans exploitation agricole propre et sans travail permanent, ce sont ces hommes qui sont toujours prêts à partir à la recherche de la « bonne fortune ».

Graphique $\mathrm{n}^{\circ}$ 5: Répartition des migrants du secteur primaire par état civil (1760 - 1836)

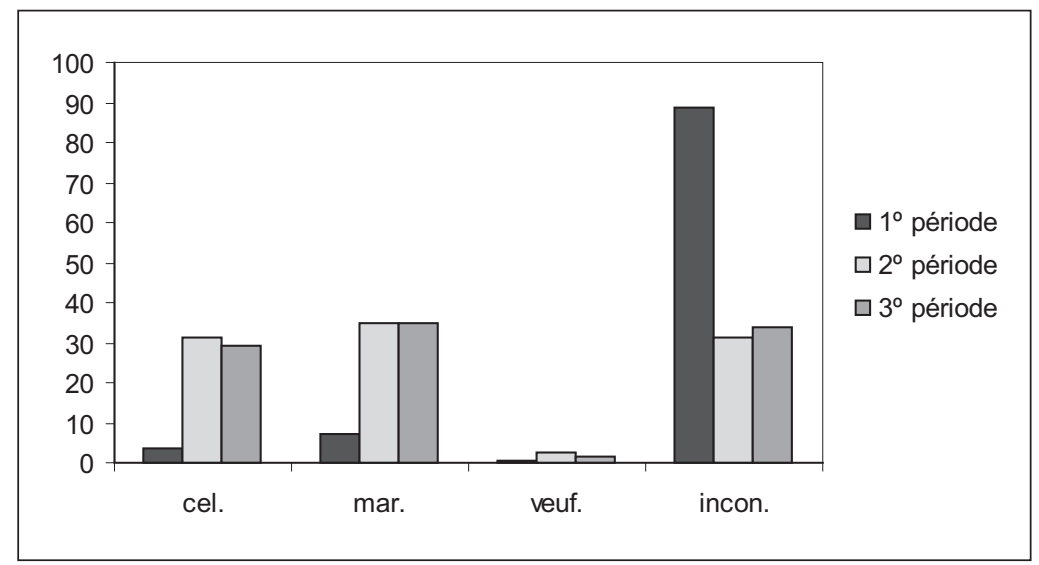

Source: AMVC: Livros de registo de passaportes $\mathrm{n}^{0}$ 1202, 1203, 1204, 1205, 1206, 1207

Mais les conditions naturelles, sociales et économiques de la région conditionnent également le départ de nombreux chefs de famille. Des petits paysans et laboureurs, mariés et avec des responsabilités familiales, mais aussi beaucoup de célibataires sans aucun lien avec la terre, constituent le profil sociologique des paysans du Minho qui connaît à peine le travail de la terre sans aucune autre qualification en dehors de la force de ses bras.

Le besoin d'argent entraîne chaque année une quantité d'habitants du Minho vers diverses régions du Portugal. En 1763/65, les deux années de plus forte migration de la première période étudiée, 139 hommes, appartenant à cette catégorie socioprofessionnelle et originaires des communes rurales de l'arrondissement, seraient partis. Mais en 1823/25 ce nombre monte et, à partir de Viana, 841 hommes sont partis des campagnes de la région.

Les mois de prédilection pour partir à la recherche de meilleures conditions de vie se situent entre juillet et novembre, les autres mois n'étant pas, cependant, pour autant négligés. Contrairement à ce que nous pourrions prévoir, parmi les comporte- 
ments divergents constatés plus haut, les travailleurs du secteur primaire contribuent également beaucoup aux deux modèles.

Graphique ${ }^{\circ}$ 6: Répartition du départ des laboureurs, travailleurs et journaliers pendant les mois de l'année (1760 - 1836)

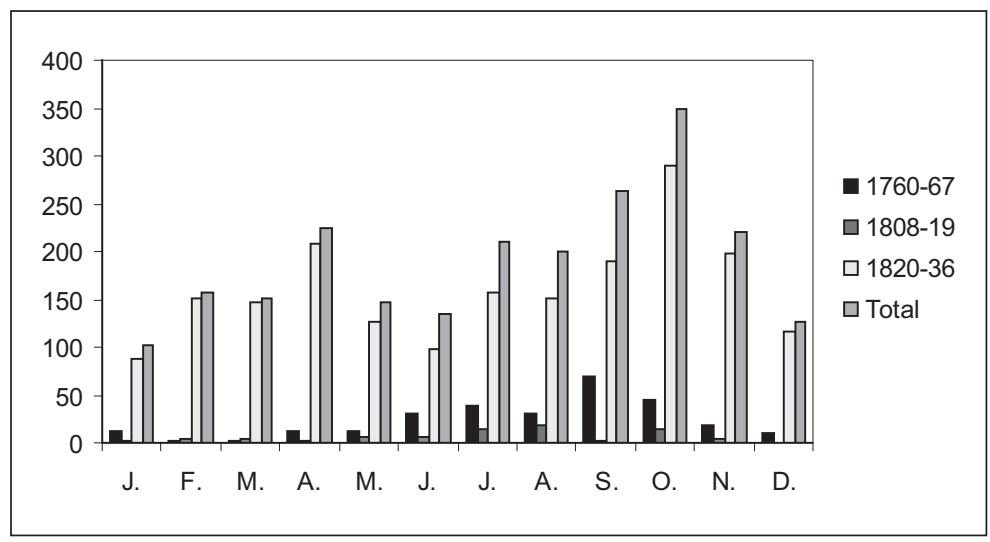

Source: AMVC: Livros de registo de passaportes n 1202, 1203, 1204, 1205, 1206, 1207

Il y a un groupe important, du moins au XIX ème siècle, qui part à partir de février, les déplacements s'intensifiant en avril. Simultanément, on remarque un comportement plus traditionnel, qui se dégage déjà à partir du XVIII ème siècle, plus conforme à la théorie de la complémentarité puisque le flux reprend en juillet et atteint son apogée en octobre. Celle-ci constitue la période au cours de laquelle la saison morte de l'agriculture du Minho s'amorce.

La cueillette des haricots et du maïs terminée ainsi que les vendanges, les champs se transforment alors en pâturages fournissant l'herbe pour l'alimentation des animaux. C'est alors que, libérés des principales tâches agricoles et sans opportunité d'emploi dans un marché du travail limité, les hommes partent (Graphique $\mathrm{n}^{\circ} 6$ ).

Bien que les hommes de la plupart des communes de l'arrondissement participent à ces flux migratoires de main d'œuvre rurale et sans qualification, les principales fournisseurs sont, au cours de toute la période en observation, surtout, les communes de Anha, Areosa, Perre ou Vila Franca do Lima. (Carte $\left.n^{\circ} 4\right)$.

Pour augmenter ces flux migratoires à partir de Viana, il y a également les paysans, les laboureurs et les journaliers des arrondissements voisins comme, par exemple, Ponte de Lima et Barcelos. Au XIXème siècle, au cours de la période de migration la plus intense, d'autres villages de l'arrondissement de Viana comme, par exemple, Afife et Ancora ou Sta Marta, Meadela et Carreço se joignent à eux. En dehors de l'arrondissement, le mouvement provenant de Ponte de Lima s'intensifie au même temps qu'un nombre non négligeable d'habitants de l'arrondissement de 
Arcos de Valdevez apparaît. C'est aussi dans cette période que près de 561 Galiciens traversent Viana (près de 29,3\% du flux de travailleurs) tantôt essayant de trouver du travail au Portugal tantôt rentrant chez eux.

Dans la première période analysée $(1760$ - 1767), Lisbonne absorbe 95\% de ces hommes. J'évoque à nouveau tout ce qui a été dit précédemment sur les facteurs d'attraction de la capitale. Chantier de construction immense, grand centre de consommation de produits et de services, la capitale est la principale destination de ceux qui tentent de trouver un travail temporaire ou même définitif. Dans les périodes suivantes (1808 - 1836), les lieux de destination semblent se diversifier sans jamais atteindre néanmoins, l'importance de la capitale. Malgré la récession constatée dans les flux du début du XIXème siècle, Lisbonne accueille, entre 1808 et 1819, 56\% des hommes de cette catégorie socioprofessionnelle. Dans la période suivante (1820 - 1836), au cours du grand élan migratoire, la capitale continue à accueillir la plupart de ces migrants $(54,2 \%)$. (Cartes $n^{\circ} 5$ et 6$)$

Cependant, au XIXème siècle, ces travailleurs partent vers quasiment toutes les régions du Portugal. Même si aucune localité n'approche la suprématie de Lisbonne, nous devons rappeler certaines des destinations choisies par les paysans de la région de Viana. Tout d'abord, la région même du Minho. Avant de partir vers d'autres endroits lointains, les paysans essaient de trouver du travail près de leur terre d'origine, de leur maison et de leur famille étant donné que le retour fait partie de leur projet. La possibilité de trouver du travail dans une région qui se caractérise essentiellement par la migration nous interpelle sur les contrastes sociaux et économiques importants que l'on peut également trouver ici. A côté des petites exploitations agricoles qui ne suffisent pas à absorber la main-d'œuvre familiale, il existe les moyennes et grandes exploitations qui, pour assumer le système de culture intensive, ont besoin d'employer temporairement ou même en permanence de la main d'œuvre salariée. C'est dans ce type d'exploitation que les valets de ferme, les journaliers et même les laboureurs trouvent du travail, tout comme les petits paysans. Ainsi, plusieurs terres de la province du Minho vont accueillir près de 10,4\% de travailleurs agricoles de l'arrondissement de Viana ou des arrondissements voisins. De la même manière, il est intéressant de remarquer un petit flux $(6,1 \%)$ qui se dirige vers la Galice à l'opposé du sens traditionnel des propres migrations galiciennes. Ce sont, en majorité, des Galiciens qui rentrent chez eux mais les Portugais sont très proches de ce groupe. Finalement, nous devons faire ressortir l'importance que prend la ville de Porto comme destination des migrants au cours de cette période. Au XIXème siècle, l'attraction que les gens qui travail la terre ressentent pour cette ville se fera également sentir dans les autres groupes qui feront l'objet de notre analyse. 


\section{Carte $n^{\circ} 4$ : Origine des paysans, laboureures et valet de ferme} qui sortent par Viana (1760-1836)

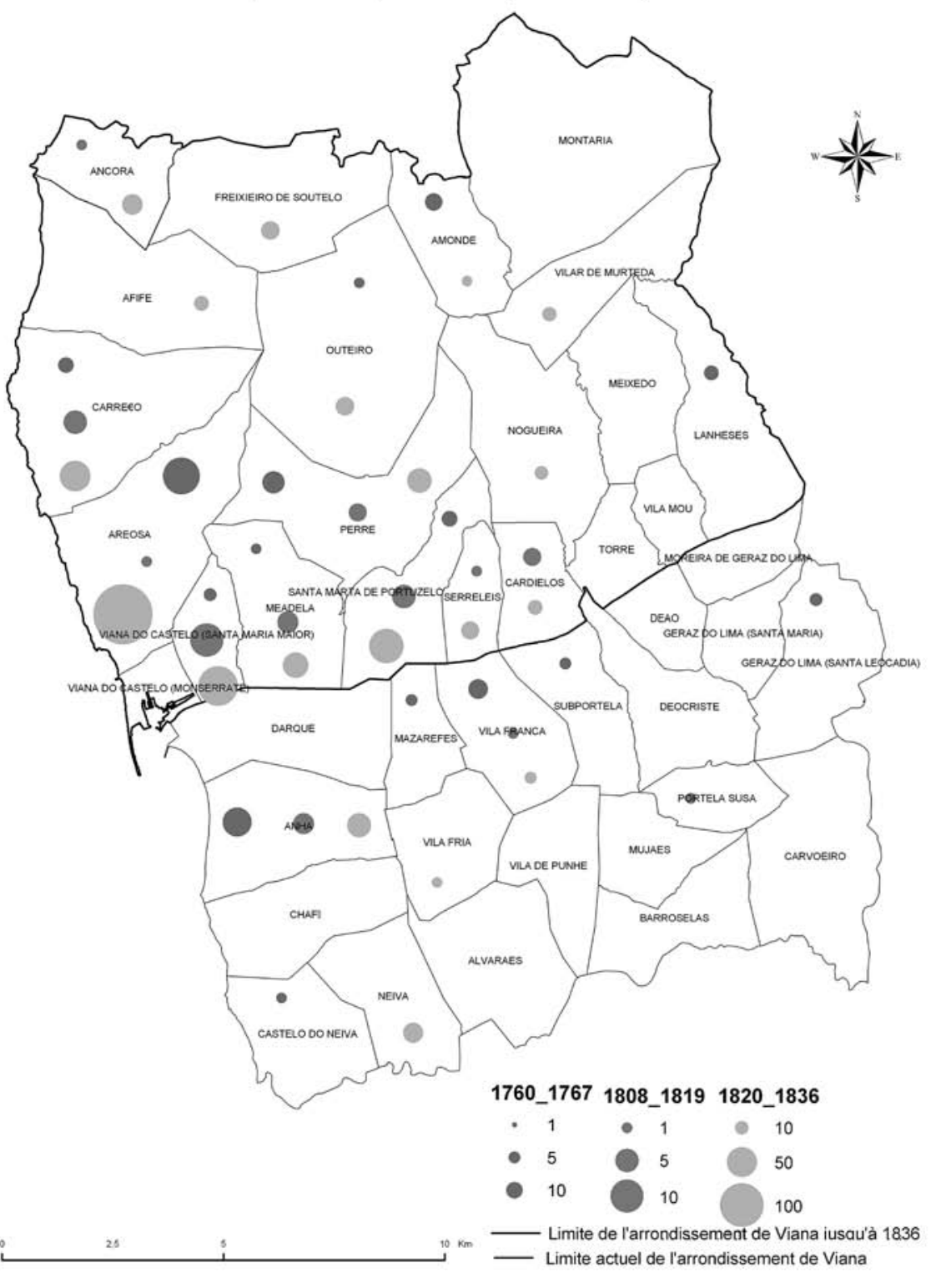




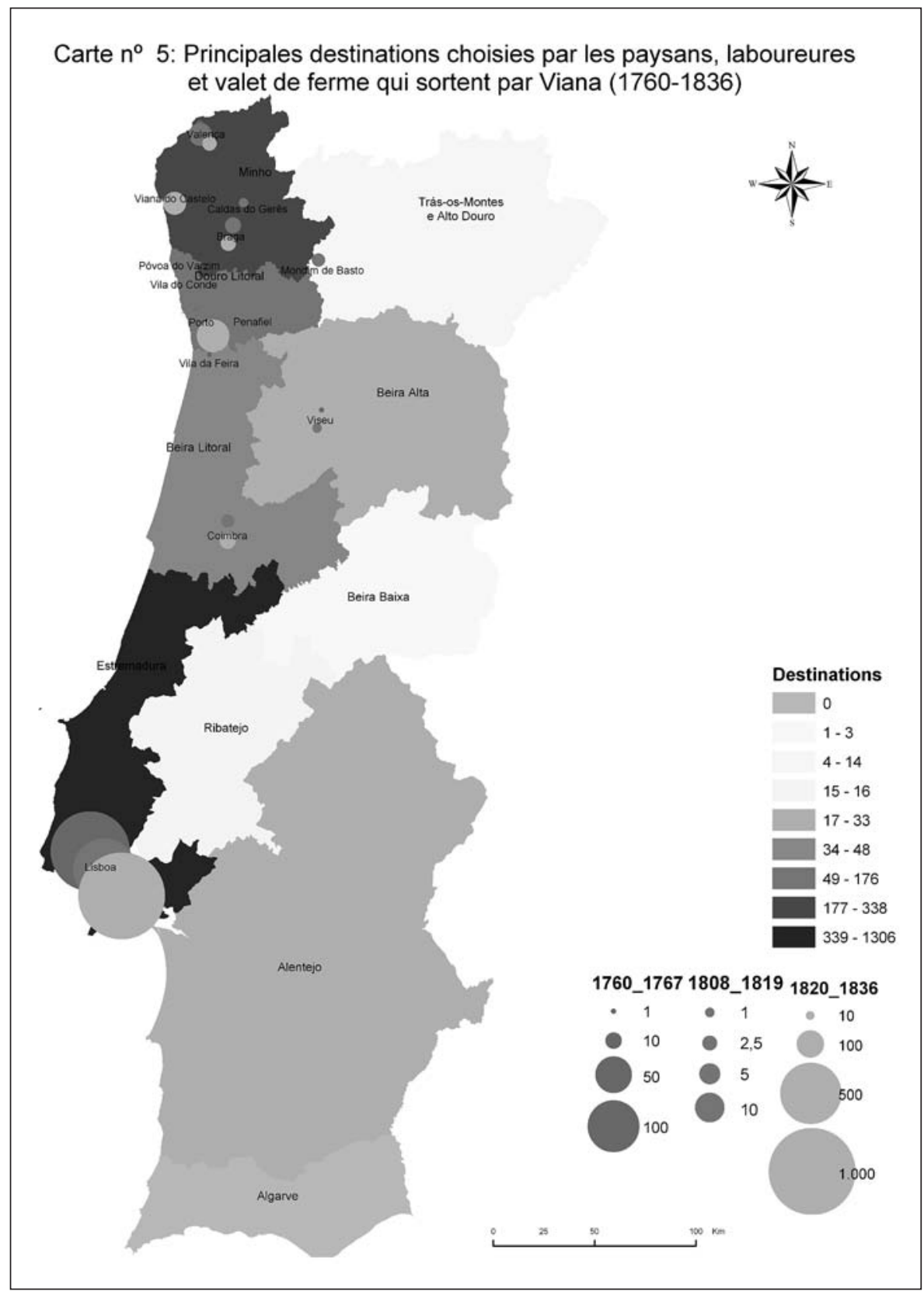


Carte $n^{\circ}$ 6: Principales villes et villages choisies comme destinations par les paysans, laboureures et valet de ferme qui sortent par Viana

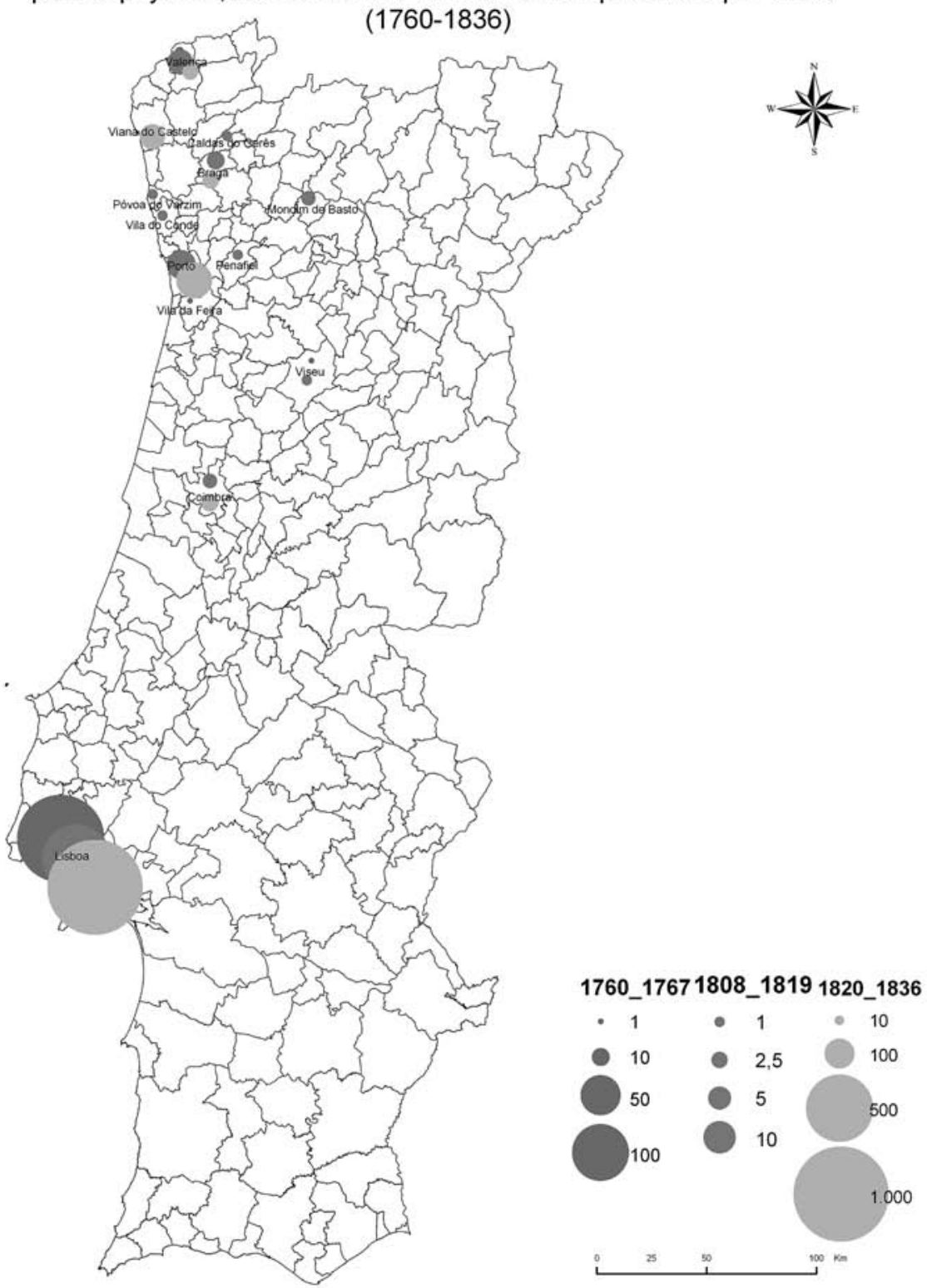




\subsection{L'art de travailler la pierre: les maçons}

Dans la région de Viana do Castelo, selon le tableau général tracé précédemment, les maçons ressortent également comme étant l'un des métiers qui participe le plus à ce type de migration (11,8\%). La spécialisation dans l'art de travailler la pierre par les habitants du Minho et l'allusion respective à leurs déplacements depuis les temps modernes, est fréquente ${ }^{44}$. Profession spécialisée, dont l'apprentissage commençait à l'enfance par des connaissances et des techniques transmises de génération en génération, de père en fils, le travail de la pierre, ou la «maçonnerie » ainsi souvent nommé, est l'apanage de quelques-uns mais, surtout, des habitants du Minho, de ceux qui ont aidé à construire la " civilisation du granit»" ${ }^{45}$. C'est pourquoi, les migrations des maçons du Minho, au cours des XVIIIéme et XIXème siècles, sont loin d'être un phénomène marginal, non seulement par rapport à la Province mais aussi par rapport au secteur de la construction dans les régions d'accueil.

Dans la région du Minho, les hauts taux de densité de la population et l'insuffisance de terre pour constituer des exploitations viables ont sans nul doute poussé à la diversification professionnelle et à la multiplication d'activités complémentaires comme recours à la survie de l'exploitation paysanne.

C'est aussi dans ce groupe que les migrations temporaires apparaissent comme une solution financière pour rembourser les dettes contractées par les familles ayant manifestement des exploitations insuffisantes. Ainsi, les hommes cherchent à modifier leurs conditions de vie, comme solution pour fonder une famille, améliorer leur quotidien, régler des impôts ou des emprunts contractés pour agrandir leur $\mathrm{casal}^{46}$.

L'analyse du profil sociologique des maçons qui migrent révèle que l'âge des migrants se situe entre 16 et 65 ans. Pourtant le tableau $n^{\circ} 4$ indique une forte incidence $(76,4 \%)$ de maçons qui se déplacent dans la tranche d'âge des 16-45 ans.

A partir de 46 ans, la tendance diminue, comme pour les laboureurs, atteignant des très faibles valeurs pour les personnes âgées de 56 ans.

Il s'agit de migrations d'adolescents et jeunes adultes, la moyenne d'âge se situant aux alentours de 32 ans. La perte de la force physique indispensable à ce type de travail mais aussi pour le trajet, explique le peu de déplacements à partir de 56 ans. Vieux et fatigués, les maçons sont remplacés par un fils ou un autre membre de la famille. Ils restent, alors, dans la quiétude du foyer, donnant un coup de main dans les travaux agricoles. La plupart des maçons sont mariés (64\%) avec des responsabilités

${ }_{44}$ OLIVEIRA, António: Op. cit., p. 7

45 ALMEIDA, Carlos Alberto Ferreira de: Arquitectura Românica de Entre-Douro-e-Minho, Porto: F.L.U.P., 1983. Thèse de Doctorat.

46 L'analyse des protocoles notariaux soulève, fréquemment, cette question. La plupart des écritures effectuées par les paysans du Minho servaient à contracter des dettes. 
Tableau $n^{\circ} 4$. Répartition des maçons par groupe d'âge (1760 - 1837)

\begin{tabular}{|c|c|c|c|c|}
\hline Âges & $1760 / 1767$ & $1808 / 1820$ & $1821 / 1837$ & Total \\
\hline $06-15$ & 0 & 1 & 19 & 20 \\
\hline $16-25$ & 15 & 19 & 221 & 255 \\
\hline $26-35$ & 16 & 10 & 253 & 279 \\
\hline $36-45$ & 6 & 13 & 146 & 165 \\
\hline $46-55$ & 5 & 4 & 78 & 87 \\
\hline $56-65$ & 1 & 3 & 19 & 23 \\
\hline Incon. & 30 & 21 & 35 & 86 \\
\hline Total & 73 & 71 & 771 & 915 \\
\hline
\end{tabular}

Source: A.M.V.C., Livros de registo de passaportes nº 1202, 1203, 1204, 1205, 1206, 1207

familiales, sociales, économiques et fiscales dans l'entretien de leurs foyers et exploitations agricoles. Mais un nombre non négligeable d'hommes célibataires, avec près de $29 \%$, participe également aux flux migratoires. Certains, trop jeunes (14/16 ans), accompagnent les maîtres et sont initiés au métier. D'autres, déjà de jeunes adultes, partent en espérant amasser un pécule qui leur permettra de fonder une famille, d'acquérir une petite exploitation ou simplement d'obtenir un travail et ramener un plus au budget de la famille. Le pourcentage des veufs, en général plus vieux et sans personne pour les remplacer dans l'exploitation agricole, est infime puisque à peine de 1,3\%. Des jeunes, mariés, avec des responsabilités familiales et des ouvriers spécialisés dont le savoir-faire est reconnu dans plusieurs parties du Royaume: tel est le portrait des maçons du Minho qui apparaît fréquemment dans quelques-unes des descriptions qui dépeignent cette société et l'histoire de cette région. C'est un aspect qui transforme certaines communes en moteurs d'une culture de migration socialement acceptée, au même titre qu'il révèle le développement des générations de cette profession au sein des mêmes familles.

Les mois choisis pour le départ à la recherche de meilleures conditions de vie se situent entre avril et septembre, époque par excellence des travaux dans la construction civile répondant, ainsi, aux demandes du lieu d'accueil.

Au travers du graphique $n^{\circ} 7$, on constate que le type des migrations des maçons du Minho ne peut être considéré comme complémentaire même si, dans la plupart des cas, il s'agit de petits propriétaires agricoles. «Partis depuis le début du printemps, leur absence correspond aux périodes de plus grande activité agricole, et leur retour, précisément à la morte saison ${ }^{47}$. Ces comportements sont similaires

47 FERNÁNDEZ CORTIZO, C.: ““GGanando la vida con el oficio de cantero”: explotacion campesina y emigración estacional en la Galicia Occidental del siglo XVIII", en EIRAS ROEL, A. (coord.): Op. cit., pp. 337-353. 
Graphique ${ }^{\circ} 7$ : Répartition mensuelle des demandes de passeport par les maçons (\%) (1760 - 1837)

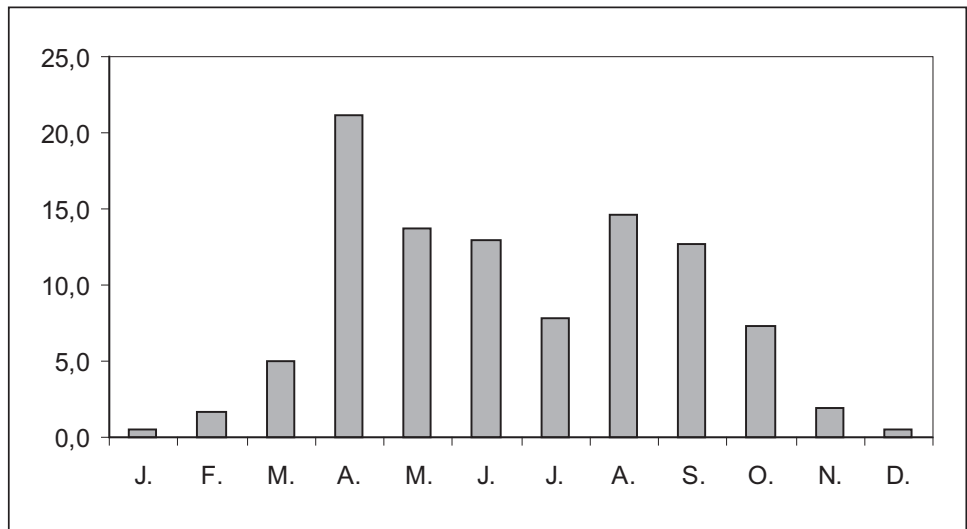

Source: A.M.V.C., Livros de registo de passaportes $n^{0}$ 1202, 1203, 1204, 1205, 1206, 1207

à ceux des personnes occupant le même emploi dans d'autres régions européennes comme, par exemple, les maçons du Limousin. « Leur départ ayant lieu au printemps et leur retour en novembre. Le migrant part lorsque les chances de profit lui semblent plus attrayantes que l'entretien de sa propre exploitation agricole où il laisse femme et enfants" ${ }^{48}$. Comme l'a aussi constaté Luigi Lorenzetti “c'est d'ailleurs un schéma qu'on retrouve dans de nombreuses zones de la région des PréAlpes méridionales qui, d'une manière générale et à des degrés différents, présentait des vocations migratoires semblables" ${ }^{49}$. Il suffit de penser aux travaux de Pérouas et Lapeyre ${ }^{50}$, de Moulin $^{51}$ et Derouet ${ }^{52}$ pour la France, de Cortizo $^{53}$ pour la Galice ou de Audenino ${ }^{54}$ pour l'Italie.

48 BÉTEILLE, Roger: Op. sup. cit., p. 427.

49 LORENZETTI, Luigi: Economie et migrations au XIX siècle: les stratégies de la reproduction familiale au Tessin, Bern, Ed. Peter Lang, Pub. Universitaires Européennes, Séries III, 1999, p. 41. Du même auteur cf. aussi: « Stratégies d'exclusion en contexte migratoire: le Val de Blenio (Tessin) au XIXè siècle », en BOUCHARD, G., DCKINSON, J., GOY, J. (dir.): Les exclus de la terre en France et au Québec XVIIè - XXè siècles. La reproduction familiale dans la différence, Sillery (Québec), Septentrion, 1998, pp. 245-269.

50 PÉROUAS, L., LAPEYRE, M-C.: « L'émigration des maçons creusois avant le XIXè siècle », Revue d'histoire moderne et contemporaine, tome XXIII, juillet - septembre, 1976, pp. 369- 393.

51 MOULIN, Marie-Anne: "Les maçons de la Haute - Marche au XVIIIè siècle ... Op. cit.

52 DEROUET, Bernard: "Les paradoxes de l'overture: exclusion familiale ... Op. cit.

53 FERNANDEZ CORTIZO, C.: Op.cit.

54 AUDENINO, Patrizia: "Séparations et solidarités dans les communautés d'émigrants saisonniers de la région de Bielle », Le Monde Alpin et Rhodanien. Familles. Destins. Destinations, $3^{\circ}$ trimestre, 1994, pp. 69-87. 
Cependant, dans le cas portugais, la dispersion significative des départs au cours des mois du printemps et de l'été nous a interpellés en vue de la possibilité de trouver des comportements divergents qui pouvaient dépendre de différentes stratégies au niveau familial ou communautaire. Nos doutes se sont confirmés lorsque nous avons effectué la répartition mensuelle des départs des maçons par les trois périodes analysées que nous venons d'étudier (Graphique $\mathrm{n}^{\circ} 8$ ).

Graphique ${ }^{\circ}$ 8: Répartition mensuelle et par période des demandes de passeport des maçons $(1760-1836)$

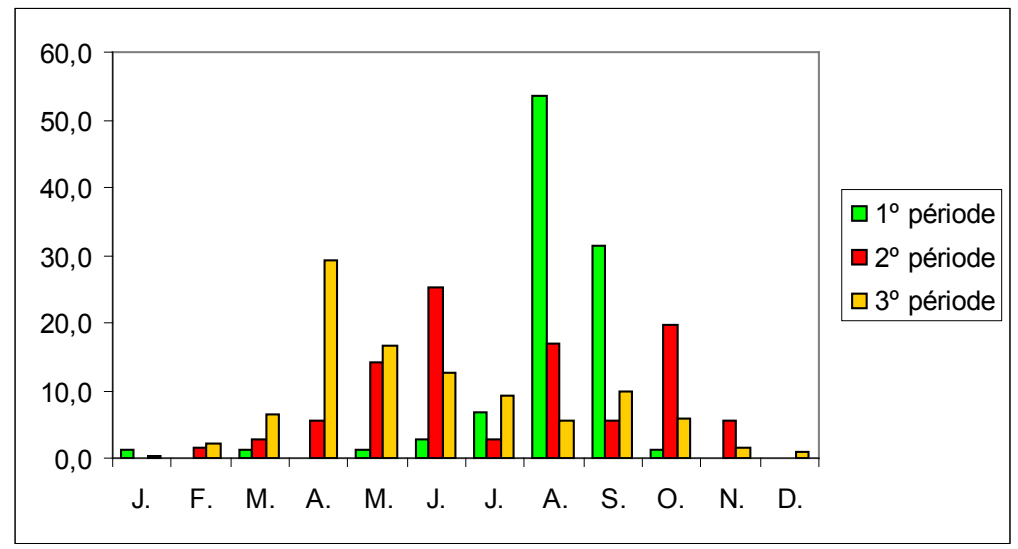

Source: A.M.V.C., Livros de registo de passaportes $n^{0}$ 1202, 1203, 1204, 1205, 1206, 1207

Au cours de la première période (1760 - 1767), nous avons surtout une migration d'automne/hiver, les maçons semblant être quelques-uns des migrants qui auraient contribué à l'exemple de complémentarité apparu plus haut dans le cadre des caractéristiques générales des migrations. La seconde période (1808 - 1820) révèle une situation complètement atypique dans laquelle nous n'arrivons pas à déterminer un modèle sûr. On constate un très grand nombre de départs aussi bien en mai/juin qu'en août/octobre. Même si nous avions élaboré l'hypothèse d'un schéma indéfinissable dû à un flux migratoire insignifiant et faible enregistré dans cette période en raison de la conjoncture politique, l'idée a été immédiatement abandonnée lorsque nous avons constaté que le groupe de maçons issu des villages de l'arrondissement de Viana était identique en nombre à celui de la fin du XVIII siècle (71/73). A l'inverse, au cours de la troisième période (1820 - 1837), nous avons le modèle de comportement typique des maçons des différentes régions européennes étudiées jusqu'à aujourd'hui.

On constate les départs au printemps pour que ces travailleurs puissent profiter de la meilleure époque de l'année (été et automne) pour travailler dans la construction civile. Le nombre de maçons (773) qui s'est engagé dans les migrations de cette 
période est dix fois supérieure aux maçons partis pendant les autres périodes. Mais comme l'aspect quantitatif des flux ne nous éclaircissait aucunement sur l'altération des comportements dans chacune des périodes analysées, nous avons affiné notre analyse en superposant les résultats obtenus sur l'origine de ces professionnels avec les destinations qu'ils avaient choisies.

On constate tout au long de la période analysée des altérations autant sur les origines que sur les destinations. Et, à notre avis, c'est à travers cet aspect qu'on peut expliquer les changements remarqués par rapport à l'époque de l'année choisie pour migrer. (Cartes $n^{\circ} 7$ et 8 )

En 1760 - 67, l'origine de la plupart des maçons est les villages de Âncora (29,2\%), Amonde (27,8\%) et Cardielos (15,3\%), les autres, peu nombreux, étant originaires des villages de Areosa, Carreço, Lanheses ou Meadela. 50\% de ces hommes se sont dirigés vers les terres de l'Alentejo comme Olivença, Juromenha, Campo Maior, Extremoz, Portalegre ou Elvas. Toutes ces destinations se situent bien dans l'intérieur de l'Alentejo près de la frontière de l'Espagne, certaines étant des sites militaires importants construits pour défendre la frontière portugaise. Or, celui qui connaît la région de l'Alentejo sait que, pendant l'été, il est impossible de travailler sous le soleil brûlant et à des températures avoisinant fréquemment les $40^{\circ}$ degrés. Les maçons, connaissant cette caractéristique, préféraient partir vers ces localités à la fin de la période estivale et travailler pendant l'automne et l'hiver, des saisons moins pénibles que l'été même quand il fait froid. C'est pourquoi, leur départ ne correspond à aucune stratégie familiale ou d'organisation du travail agricole mais plutôt à des conditions naturelles des lieux d'arrivée. Cependant, on commence à observer, à cette période déjà, une nouvelle tendance qui s'affirmera plus tard, au XIXème siècle. Près de $14 \%$ des maçons ont préféré se diriger vers la région de Coimbra et ses alentours alors que $7 \%$ de ces artistes ont commencé à s'orienter vers un nouvel endroit du marché qui se révèlera très attractif à partir de 1820: la Beira Alta.

Au cours de la seconde période (1808 - 1819), bien qu'elle constitue une phase de grande récession dans les migrations des habitants du Minho, 71 maçons ont quitté les villages de l'arrondissement de Viana. Près de $21 \%$ étaient natifs du village de Soutelo. D'autres, en même quantité, venaient de Ancora et Amonde, villages qui, déjà, dans la période précédente, s'étaient révélés comme étant les principales sources de ces ouvriers spécialisés. Perre, Outeiro, Nogueira, Sta Marta, Cardielos, Meadela et Serreleis constituent les villages qui, conjointement aux premiers, contribuent à la définition d'une région de l'arrondissement de Viana véritablement spécialisée dans l'art de travailler la pierre. Encore une fois, c'est l'Alentejo et surtout les villes frontalières qui absorbent près de $50 \%$ des maçons. Coimbra reste l'une des destinations de prédilection attirant, cette fois, près de $17 \%$ du groupe, alors 
Carte $n^{\circ}$ 7: Les communes d'origine des maçons qui sortent par Viana

(1760-1836)

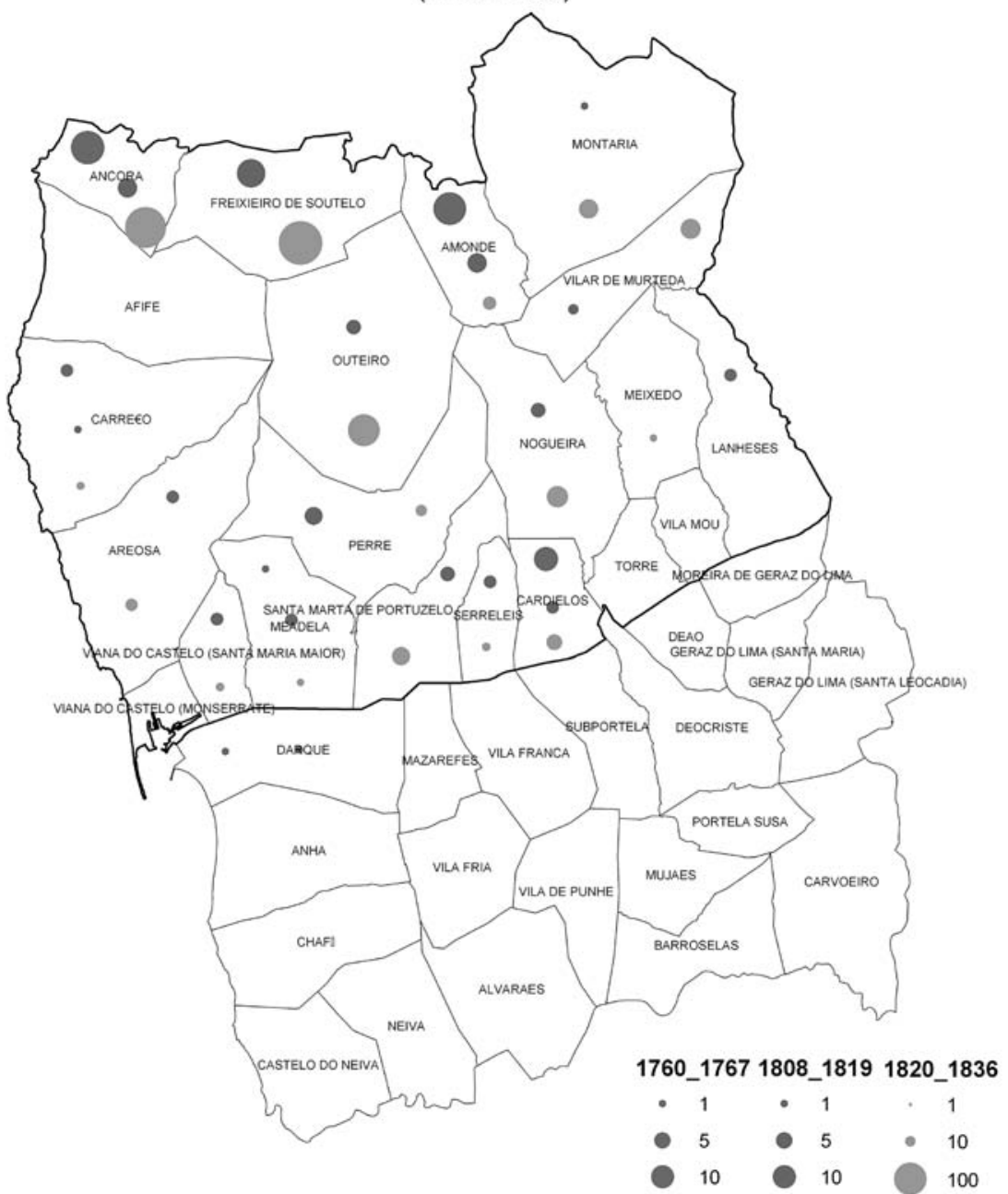

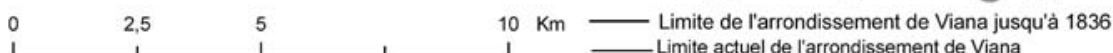




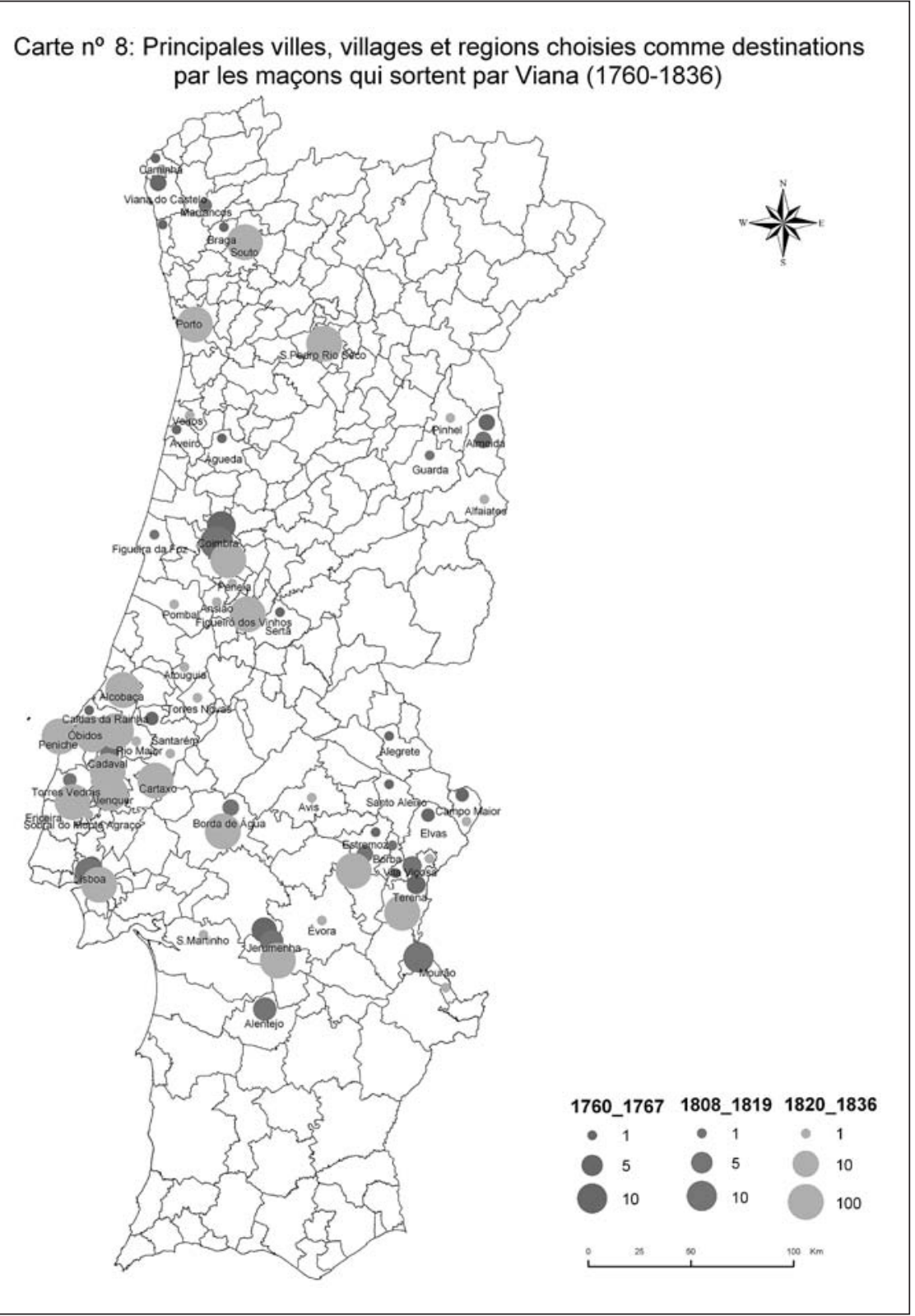


que les autres maçons se dispersent dans plusieurs bourgs et villages du Ribatejo et de l'Extremadura. Ce n'est pas étonnant, donc, que leurs départs se répartissent sur plusieurs mois à partir début du printemps jusqu'au début de l'automne. Ceux qui partent vers l'Extremadura ou le Ribatejo, peuvent le faire au printemps et en étant donné qu'il s'agit de régions ou la période estivale est plus douce.

Cependant, c'est au cours des années 20 du XIXème siècle que l'on va enregistrer les principales altérations dans les comportements des maçons. Si, d'un côté, on confirme la spécialisation et le résultat d'un apprentissage qui s'effectuait depuis longtemps parmi les habitants de Soutelo (23,5\%), Âncora (20,3\%), Outeiro (12,4\%), Nogueira (5,6\%) ou Sta Marta (4, 3\%), d'un autre côté, il faut enregistrer l'apparition des habitants du village de S. Lourenço da Montaria (4,5\%), voisin des autres et qui, jusqu'à cette période, n'étaient pas apparus parmi les spécialistes du travail de la pierre. Mais ce ne sont pas les seuls ! Près de $6 \%$ des maçons de l'arrondissement sont également issus du village voisin de Vilar de Murteda. Le développement et l'ouverture de cette activité à un nombre toujours plus important de villages, prouve non seulement la rentabilité du travail de la pierre mais permet aussi de constater le fonctionnement des réseaux de communication et de solidarité entre les communautés villageoises voisines. L'augmentation de l'activité a permis le maintien de la tradition de départ à la fin de l'été, et au début de l'automne vers les terres de l'Alentejo, tout en réactivant les potentialités des niches qui s'affirmaient de plus en plus, intensifiant les départs du printemps/été vers la Beira Litoral et le Ribatejo. L'intensité des migrations des maçons, à cette période, permet la découverte de nouveaux marchés qui semblent se répartir sur quasiment tout le territoire national.

Du Minho à l'Alentejo, leur art est reconnu et donc leur travail apprécié et demandé procurant ainsi une source importante de profit pour les familles qui possèdent un ou plusieurs artistes. Ainsi, les comportements divergents de ces professionnels semblent être davantage articulés autour des conditions naturelles des régions choisies pour exercer leur activité plutôt qu'autour de quelque autre type de stratégie individuelle ou familiale. Cependant, il ne faut pas oublier que les maçons qui choisissent les régions de l'intérieur brûlant de l'Alentejo restent dans leurs villages et leurs maisons pendant l'époque des principaux travaux agricoles ; leurs migrations constituent de véritables compléments à l'activité des champs et au profit qu'ils en retirent. Le cas est différent pour ceux qui partent au printemps. Les travaux agricoles sont pris en charge par les femmes ainsi que par les grands-parents et par les enfants.

Parmi les réseaux des voisins et des familles constitués pour organiser les équipes qui partaient travailler dans certains des plus importants chantiers du Royaume, des secteurs de spécialisation ont été définis. Parallèlement, on transmettait aux générations plus jeunes l'art de travailler la pierre, savoir ce qui est devenu un véritable patrimoine symbolique mais surtout d'ordre matériel puisqu' il constituait la vérita- 
ble source de profit de nombreuses familles de la région nord de l'arrondissement de Viana. Mais, comme le dit Luigi Lorenzetti, cette "tradition de longue durée a aussi besoin d'être expliquée par la création de véritables réseaux de clientèles, permettant le maintien des niches de marché"55. C'est pourquoi, chaque famille et chaque communauté, “en plus des techniques du métier, transmettait également les places de marché que les migrants avaient conquis au cours du temps $»^{56}$.

\subsection{Marchands, marchands forains, colporteurs et employés de commerce}

Le mouvement de ceux qui se tournent vers le secteur tertiaire est un aspect tout aussi important que les groupes socioprofessionnels qu'on vient d'analyser. Bien que notre étude débute à une période au cours de laquelle le marché de Viana connaît une récession, le mouvement des entrées et des départs de négociants, forains, colporteurs et caissiers est encore le reflet de l'importance acquise par le port de Viana dans le contexte du commerce national, au cours des siècles précédents.

«En 1750, une grande variété d'agents et même de compagnies d'affaires sont largement engagées dans des activités d'importation et d'exportation. Dans le contexte du commerce national, ils s'articulent autour des grands marchés nationaux, surtout Lisbonne et Porto, vers lesquels sont transportés les produits d'exportation locale. Dans le commerce externe, c'est avec la Galice que ces petits et moyens commerçants font leurs principales affaires $\rangle^{57}$. Mais à leur côté, pour le grand commerce et pour les trafics plus éloignés, on rencontre les négociants anglais et du Nord de l'Europe. Les tissus, la morue et la sardine, les blés, fromages et beurres et le fer sont les principaux produits d'importation. Ces derniers, aussitôt arrivés à Viana, sont distribués vers l'intérieur des terres à travers « un vaste réseau d'agents commerciaux de Viana qui travaille sur tout le territoire d'Entre-Douro-et-Minho ». Il s'agit d'un réseau très développé de petits et moyens commerçants qui travaillent sur les foires et marchés régionaux en vendant des produits importés et en ramassant les produits régionaux pour les exporter ${ }^{58}$.

Néanmoins, selon José Viriato Capela, tout ce dynamisme va être interrompu par la politique commerciale de Pombal. A cause de la concession de monopoles à des Compagnies implantées sur les grands marchés de Porto et de Lisbonne, les petits ports régionaux, comme celui de Viana, commenceront à disparaître. En 1761 - 1764, le marché de Viana connaît une grave récession provoquée par un ensemble

55 Ibídem, p. 41

56 LORENZETTI, Luigi: Economie et migrations au XIXe sièles ... Op. cit, p. 41

57 CAPELA, José Viriato Eiras: "O porto de Viana no contexto do comércio externo português (análise à balança comercial de 1783), en Viana - o mar e o porto, Viana do Castelo, 1987, p. 94.

58 Ibídem, p. 95 
de crises «qui sont en même temps des crises du commerce extérieur, surtout du commerce anglais, mais aussi des crises agricoles internes qui aggravent le faible pouvoir d'achat et les disponibilités monétaires internes en raison d'une mauvaise vente de produits régionaux d'exportation ${ }^{59}$. Voilà l'explication de la croissance des migrations internes, au XVIIIè siècle, que nous avons vue plus haut.

A travers le registre des passeports internes, on sent le dynamisme d'une activité qui tente de survivre, malgré la conjoncture difficile qui a lieu sur le marché de Viana.

Tableau $n^{\circ} 5$ : Répartition des commerçants, forains, colporteurs et employés de commerce par sexe et période (1760 - 1736)

\begin{tabular}{|l|c|c|c|c|c|c|c|c|}
\hline Sexe & $1760 / 67$ & $\%$ & $1808 / 19$ & $\%$ & $1820 / 36$ & $\%$ & Total & $\%$ \\
\hline Hommes & 63 & 94 & 129 & 98 & 1462 & 99,7 & 1654 & 99,3 \\
\hline Femmes & 4 & 6 & 3 & 2 & 4 & 0,3 & 11 & 0,7 \\
\hline Total & 67 & 100 & 132 & 100 & 1466 & 100 & 1665 & 100 \\
\hline
\end{tabular}

Source: A.M.V.C., Livros de registo de passaportes $n^{0}$ 1202, 1203, 1204, 1205, 1206, 1207

Encore une fois, nous sommes devant une activité et une mobilité particulièrement masculine, comme le prouve l'analyse du tableau $n^{\circ} 5$. Cependant, il faut rappeler qu'à la modeste participation des femmes qui demandaient un passeport en se déclarant comme marchandes nous devons ajouter un nombre significatif de femmes qui accompagnent les forains et les colporteurs lors de leurs déplacements sur les terres de la Province ou du Royaume. C'est dans ces groupes de travail que l'on trouve le plus grand nombre d'accompagnateurs de sexe féminin en général.

Les techniques commerciales et la connaissance des marchés passent, en général, de père en fils en maintenant ainsi l'activité de marchand dans la famille tout au long de plusieurs générations. C'est un groupe qui, traditionnellement, se reproduit en son propre sein, les entrées de nouveaux membres d'autres secteurs de la société n'étant pas pour autant exclues. Si l'on n'appartient pas à une famille de commerçants, il faut commencer très tôt, comme employé, dans les magasins des grandes places commerciales de Lisbonne et de Porto.

C'est un des postes possibles pour ceux qui n'ont pas de terre et qui, très jeunes entre 14 et 20 ans, partent vers la capitale apprendre « le négoce » comme l'on peut le constater sur certains registres de passeports de notre échantillon.

Avec un âge moyen inférieur (31) à celui des autres groupes analysés, la plupart $(62,5 \%)$ des marchants, forains, colporteurs ou employés commerciaux se déplacent entre les 16 - 45 ans, comme les autres groupes analysés, tant qu'ils ont la force physique pour supporter les longs trajets. Après 45 ans, les affaires loin des magasins

59 Ibídem., p. 97 
Tableau $n^{\circ}$ 6: Répartition des migrants du tertiaire par âge et par période (1760 - 1836)

\begin{tabular}{|c|c|c|c|c|}
\hline Âges & $1760 / 67$ & $1808 / 1819$ & $1820 / 1836$ & Total \\
\hline $0-15$ & 6 & 7 & 26 & 39 \\
\hline $16-25$ & 28 & 22 & 294 & 344 \\
\hline $26-35$ & 16 & 21 & 364 & 401 \\
\hline $36-45$ & 12 & 15 & 268 & 295 \\
\hline $46-55$ & 3 & 11 & 107 & 121 \\
\hline $56-65$ & 1 & 1 & 34 & 36 \\
\hline $66-75$ & 1 & 1 & 2 & 4 \\
\hline Incon. & 0 & 54 & 371 & 425 \\
\hline Total & 67 & 132 & 1466 & 1665 \\
\hline
\end{tabular}

Source: A.M.V.C., Livros de registo de passaportes $n^{0}$ 1202, 1203, 1204, 1205, 1206, 1207

sont laissées aux mains du fils successeur ou de l'employé, personne de confiance qui travaille avec le commerçant depuis son enfance.

Jeunes et majoritairement célibataires tels sont les principaux traits du profil sociologique qui différencient légèrement les migrations des professionnels du tertiaire par rapport à la mobilité des paysans et laboureurs de la construction civile. Par rapport à cet aspect, il faut souligner que c'est dans ce groupe que nous allons trouver les caractéristiques relevées pour les migrations extérieures de longue durée ou définitives. Serait-ce de ce groupe que partent ceux qui, arrivés à Porto ou à Lisbonne, embarquent vers des terres lointaines?

Tableau $n^{0} 7$. Répartition du nombre d'hommes

travaillant dans le commerce selon I'état civil et les périodes (1760 - 1836)

\begin{tabular}{|l|cc|cc|cl|cl|}
\hline Etat civil / Périodes & \multicolumn{2}{|c|}{$1760-1767$} & \multicolumn{2}{|c|}{$1808-1819$} & \multicolumn{2}{|c|}{$1820-1836$} & \multicolumn{2}{|c|}{ Total } \\
\hline Célibataires & 1 & $(1,5 \%)$ & 41 & $(31 \%)$ & 528 & $(36 \%)$ & 570 & $(34,3 \%)$ \\
\hline Mariés & 3 & $(4,5 \%)$ & 45 & $(34 \%)$ & 510 & $(34,8 \%)$ & 558 & $(33,5 \%)$ \\
\hline Veufs & 0 & $(0,0 \%)$ & 3 & $(2,4 \%)$ & 59 & $(4 \%)$ & 62 & $(3,7 \%)$ \\
\hline Inconnu & 63 & $(94 \%)$ & 43 & $(32,6)$ & 369 & $(25,2 \%)$ & $475 \quad(28,5 \%)$ \\
\hline Total & 67 & $(100 \%)$ & $132 \quad(100 \%)$ & $1466 \quad(88,05 \%)$ & $1665(100 \%)$ \\
\hline
\end{tabular}

Source: A.M.V.C., Livros de registo de passaportes $n^{0}$ 1202, 1203, 1204, 1205, 1206, 1207

Mais la différence la plus significative du comportement migratoire de ce groupe par rapport aux précédents est confirmée par la permanence et la constance de l'activité. La répartition des registres de passeports pendant les mois de l'année au cours desquels ils sont demandés, montre que l'activité est exercée tout au long de l'année avec une légère augmentation pendant les mois de mai jusqu'à octobre, période à laquelle ont lieu les grandes foires du Minho.

Bien que certains puissent être propriétaires d'exploitations agricoles, les affaires constituent l'occupation principale et exclusive. Nous ne sommes pas devant une 
occupation complémentaire de l'activité agricole, même si, au cours de la première période de notre analyse (1760 - 1767), à peine 25,4\% des commerçants résident à Viana. Les autres sortent des communes rurales de l'arrondissement et des arrondissements voisins comme Barcelos, Ponte de Lima ou Caminha. Cet aspect vient corroborer les indications que nous détenons concernant la crise des réseaux commerciaux de cette période. Comme les réseaux et l'échange entre les produits importés et les produits régionaux d'exportation ne fonctionnent pas, les commerçants ruraux ont besoin de se déplacer eux-mêmes à Lisbonne pour vendre les produits locaux. (Carte $\mathrm{n}^{\mathrm{o}} 9$ et 10)

Graphique $n^{\circ} 9$ Répartition des migrants du tertiaire, qui ont demandé un passeport, par mois de l'année

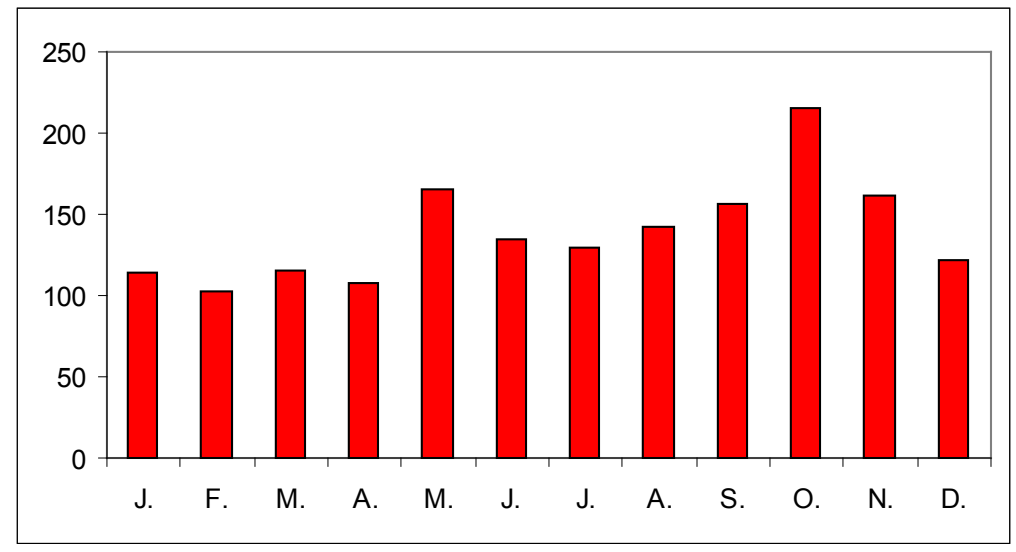

Source: A.M.V.C., Livros de registo de passaportes nº 1202, 1203, 1204, 1205, 1206, 1207

Dans la $2^{\circ}$ période (1808 - 1819), le flux augmente légèrement tout comme les commerçants résidant à Viana $(39,4 \%)$; toutefois, une importante participation des commerçants des communes rurales et des arrondissements voisins est maintenue. La grande nouveauté, à cette période, c'est la réapparition des commerçants de la Galice, éloignés au moment des mesures de Pombal à propos du contrôle commercial dans les zones frontalières. Lisbonne, vers laquelle se dirigent 35,6\% du flux de cette période, continue d'être la principale place de vente des produits régionaux. Mais la ville de Porto, lieu commercial qui avait profité des privilèges de Pombal au détriment de Viana, commence à exercer une nouvelle attraction car 9,8\% des commerçants du Haut Minho, qui demandent un passeport à Viana, vont vers Porto.

Entre 1820 et 1836, le marché de Viana semble sortir de la léthargie dans laquelle il avait été plongé à la fin du XVIIIème siècle, révélant par le registre des passeports une forte activité commerciale. Le nombre de commerçants de tout genre engagé dans les déplacements internes est 12 fois supérieur à celui des périodes précéden- 


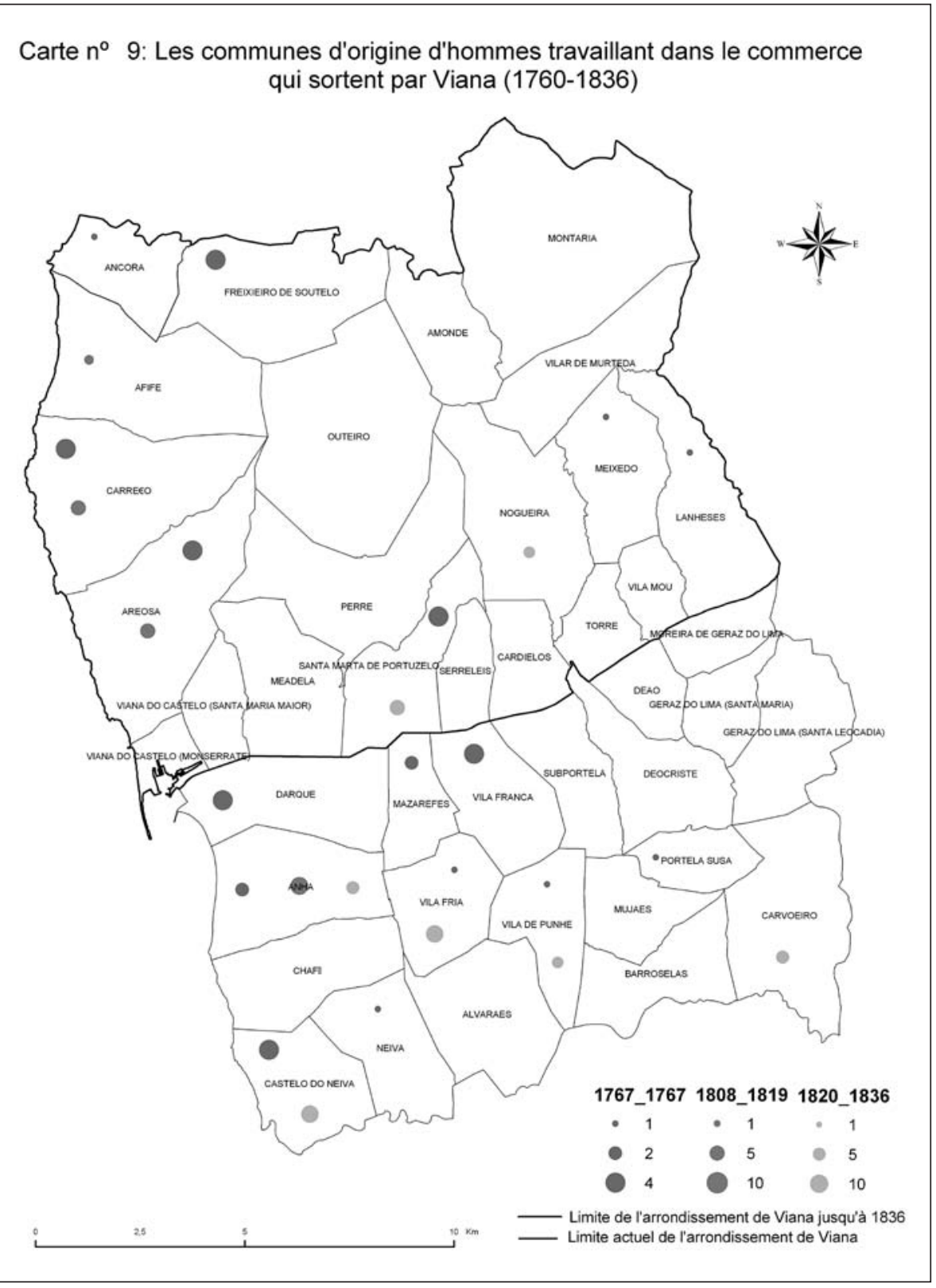


Carte $n^{\circ}$ 10: Principales villes, villages et regions de destinations d'hommes travaillant dans le commerce (1760-1836)

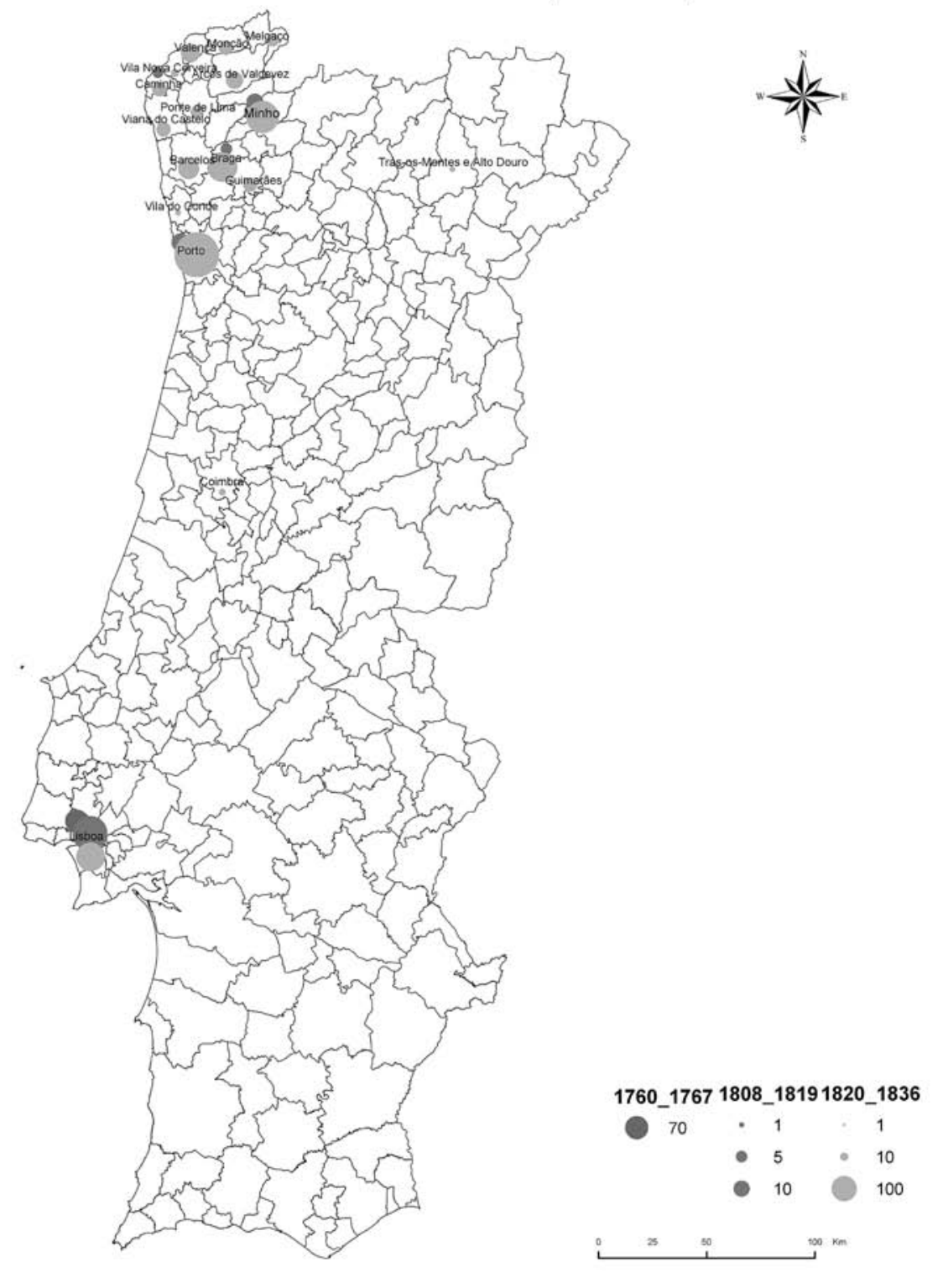


tes (1466). Les réseaux de petits et moyens commerçants qui établissaient les liaisons avec l'intérieur de la province semblent rétablis.

Le commerce avec la Galice ainsi que le grand commerce externe qui se faisait grâce aux commerçants anglais semble également avoir (re)démarré. En dehors des commerçants originaires de la ville de Viana (673) et de certains villages de l'arrondissement (56), qui partent vers Porto et toutes les terres du Minho, y résident ou y circulent des hommes d'affaire de toutes origines. Parmi les Portugais en nombre significatif, il y a ceux originaires des villes frontalières comme Melgaço (12), Valença (29) et Monção (20), des bourgs de l'intérieur du Minho comme Ponte de Lima (16), Arcos de Valdevez (25), Braga (54) ou Guimarães (13) et surtout les commerçants de Porto (108). Parmi les étrangers, arrivent et partent de Viana surtout des Espagnols (69 parmi lesquels 55 Galiciens), des Anglais (62), des Français (57), des Italiens (29) et des Marocains (14).

De tout ce flux, Lisbonne reçoit, à cette époque, à peine $8,9 \%$ des commerçants. Ils se dirigent et se déplacent, surtout, dans la région de l'Entre Douro et Minho dans laquelle se détachent les marchés de Porto avec $21,4 \%$ des commerçants qui s'y rendent et le marché de Braga qui reçoit la visite de 9,4\% de ces hommes d'affaires.

Avec la fin du monopole commercial des Compagnies Pombalines après le traité avec l'Angleterre en 1810, l'ancienne activité commerciale, petit à petit, paraît resurgir. Partant le commerce se fait avec d'autres réseaux et des liaisons avec d'autres places commerciales qui se sont développées à cette époque-là. Néanmoins, à partir de 1822, après l'indépendance du Brésil, le Portugal va essuyer une des plus graves crises économiques. La perte du principal marché consommateur des marchandises portugaises va paralyser l'économie et provoquer une autre période de pénurie dans la région du Minho. Pendant que les paysans et les laboureurs cherchent du travail qui puisse fournir un peu d'argent les marchands ont besoin de trouver, à l'intérieur même du pays, une nouvelle clientèle pour les produits nationaux et d'origine étrangère.

\section{Conclusion}

Enfin, comme Laurence Fontaine, nous pouvons dire que la vie des habitants de Viana et de ses « villages est basée sur une culture d'absence, de départ toujours possible et de retour jamais certain. Quelque soit l'objectif de l'absence, le départ possible sans retour jette son ombre sur tous les actes de la vie, dans toutes les familles, même les plus aisées» ${ }^{60}$.

Ainsi pour interpréter tous les mécanismes des processus des migrations il faut aller un peu plus loin dans notre analyse. Après avoir dégagé quelques-unes de leurs

60 FONTAINE, Laurence: « Solidarités familiales et logiques migratoires en pays de montagne à 1'époque moderne », Annales ESC, Nov. - déc., nº 6, pp. 1433-1450. 
spécificités, nous essayerons d'analyser, tout d'abord, les réseaux de solidarité familiale et de voisinage qui ont été tissés pour aider à mener avec succès les déplacements et la recherche de travail. Mais comme sont ces migrations saisonnières, temporaires ou même définitives qui ont modelé la société minhota nous devons rechercher les liens de liaisons avec les formes de reproduction sociale et analyser leur influence sur les stratégies d'héritage. Surtout, il faut trouver le rôle des migrations dans le choix du successeur et héritier unique ou préciputaire, octroyant aux femmes une place et un pouvoir leur imposant des obligations et des devoirs qu'elles doivent assumer en l'absence des hommes de la famille. 